\title{
Young Lunar Mare Basalts in the Chang'e-5 Sample Return Region,
}

\section{Northern Oceanus Procellarum}

\author{
Yuqi Qian ${ }^{1,2}$, Long Xiao ${ }^{1,3^{*}}$, James W. Head ${ }^{2 *}$, Carolyn H. van der Bogert ${ }^{4}$, Harald Hiesinger ${ }^{4}$, \\ Lionel Wilson ${ }^{5}$ \\ ${ }^{1}$ State Key Laboratory of Geological Processes and Mineral Resources, School of Earth \\ Sciences, China University of Geosciences, Wuhan, 430074, China \\ ${ }^{2}$ Departmental of Earth, Environmental, and Planetary Sciences, Brown University, \\ Providence, 02912, USA \\ ${ }^{3}$ Center for Excellence in Comparative Planetology, Chinese Academy of Sciences, Hefei, \\ 230026, China \\ ${ }^{4}$ Institut für Planetologie, Westfälische Wilhelms-Universität Münster, Münster, 48149, \\ Germany \\ ${ }^{5}$ Lancaster Environment Centre, Lancaster University, Lancaster LA1 4YQ, UK
}

Corresponding Author: Long Xiao (longxiao@cug.edu.cn), James W. Head (James_Head@brown.edu)

\begin{abstract}
Chang'e-5, China's first lunar sample return mission, is targeted to land in northern Oceanus Procellarum, within a region selected on the basis of 1) its location away from the ApolloLuna sampling region, 2) the presence of the Procellarum KREEP Terrane (PKT), 3) the occurrence of one of the youngest lunar mare basalts (Em4), and 4) its association with Rima Sharp. In order to provide context for returned sample analyses, we conducted a comprehensive study of the regional and global settings, geomorphology, composition, mineralogy, and chronology of the Em4 mare basalts. Superposed on Imbrian-aged low-Ti basalts, Em 4 covers $37,000 \mathrm{~km}^{2}$ and is composed of Eratosthenian-aged ( 1.53 Ga), high-Ti basalts with a mean thickness of $\sim 51 \mathrm{~m}$ and a volume between $\sim 1450$ and $2350 \mathrm{~km}^{3}$. Minor variations in $\mathrm{TiO}_{2}$ and $\mathrm{FeO}$ abundance occur within the unit and the thorium content averages $\sim 6.7 \%$, typical of PKT mare basaltic regolith. No specific source vents (e.g., fissures, cones, domes) were found within the unit. We show that Rima Sharp is actually composed of three major rilles, whose source vents are located outside of, and which flow into, and merge in Em4, suggesting that they may be among the sources for Em4. Regolith thickness averages $\sim 7 \mathrm{~m}$ and there is abundant evidence for vertical and lateral mixing; the most likely sources of distal ejecta are Aristarchus, Harpalus, and Sharp B craters. Returned samples from local and distant materials delivered by impact will thus provide significant new insights into lunar geochronology, inner Solar System impact fluxes, the age of very young mare basalts, the role of the PKT in the generation of mare basalts, the role of sinuous rilles in lava flow emplacement, and the thermal evolution of the Moon.
\end{abstract}

Key Points Chang'e-5, Moon, Lunar Landing Site, Young Mare Basalts, Chronology 


\section{Introduction}

Following Chang'e-4, the first mission to explore the lunar farside, the Chang'e-5 (CE5) mission plans to collect $\sim 2 \mathrm{~kg}$ of lunar samples (Pei et al., 2015) from the unexplored northern Oceanus Procellarum (OP) 44 years after the last sampling by Luna-24 in 1976, an area outside the Apollo and Luna sampling region, and deep within the unique Procellarum KREEP Terrane (PKT). The candidate CE-5 landing area $\left(41-45^{\circ} \mathrm{N}, 49-69^{\circ} \mathrm{W}\right.$, Fig. 1A) is located in a relatively flat mare plain that is part of the largest contiguous expanse of basaltic maria on the Moon (Whitford-Stark and Head, 1980). OP is distinct in many additional ways: it 1) is a non-mascon mare (Neumann et al., 2015), 2) has the thinnest regional crust (typically <30 km; Wieczorek et al., 2013), 3) displays three major volcanic complexes (Whitford-Stark and Head, 1980), 4) is located in the midst of the highest concentration of the silica-rich red spots (Glotch et al., 2011), and 5) is the region with the highest abundance of sinuous rilles including the longest and largest ones (Hurwitz et al., 2013). In addition, OP shows a diversity of smaller gravity anomalies attributed to buried lava-filled impact craters (Evans et al., 2016), lies within a region characterized by a distinct polygonal gravity gradient anomaly (Andrews-Hanna et al., 2013), and is home to two of the youngest impact basins (Imbrium and Iridum). Perhaps most importantly, the CE-5 region lies within the PKT (Jolliff et al., 2000), a unique and distinctive global terrane comprising 16\% of the Moon characterized by elevated thorium values (3-12 ppm). Basalts in OP span a range of ages from 4 4-2-1.0 Ga (Hiesinger et al., 2011), the widest range known on the Moon, and include a suite of the youngest mare basalts $(\sim 2.0-1.0 \mathrm{Ga})$ (Fig. 1B).

Together, these characteristics of the northern OP suggest that both the crust (PKT and thin crust) and mantle (mare basalt source regions) here are unique, and that one or both crustal characteristics (PKT and/or thin crust) were responsible for the concentration of latestage volcanic features and deposits in this region. Globally, the relatively small lunar radius means that the Moon rapidly cools conductively and forms a continuous lithosphere that thickens with time, with the net state of stress in the lithosphere becoming increasingly contractional (Head and Wilson, 2017). These factors combine to retard the production of magma with time, as well as its ascent and surface eruption (Head and Wilson, 2017; Wilson and Head, 2017). Thus, volcanic deposits with ages younger than $\sim 2.0 \mathrm{Ga}$ are rare on the Moon (e.g., Hiesinger et al., 2011). On the other hand, elevated radioactive element abundances of the PKT may induce (Wieczorek and Phillips, 2000) and prolong the volcanic activity in the region (Ziethe et al., 2009), an interpretation supported by the concentration of young mare basalts in the center of the PKT (Hiesinger et al., 2011, 2003; Morota et al., $2011)$ and the concurrent high Th content of the associated basaltic regolith ( 2-6 ppm; Haskin et al., 2000).

Indeed, Em3 $(1.51 \mathrm{Ga})$ and Em4 $(1.21 \mathrm{Ga})$ are among the youngest mare units in the PKT (Qian et al., 2018), and these types of young PKT mare basalts are characterized by high-Ti contents and high olivine (OLV) abundance, distinct from the older high-Ti mare basalts (e.g., Staid et al., 2011). Besides, the basalts tend to have higher Ti and OLV abundances with decreasing age (e.g., Staid et al., 2011). Thus, samples from these young lunar mare basalts have enormous scientific potential for an improved understanding of lunar impact chronology and thermal evolution (van der Bogert and Hiesinger, 2020). However, no igneous samples younger than $2.9 \mathrm{Ga}$ (NWA773) have yet been acquired (Borg et al., 2004), 
which impedes our full understanding of the last half of lunar history.

On the basis of mineralogical and geochemical characteristics and impact crater populations, Zhao et al. (2017) and Qian et al. (2018) mapped nine geological units in the CE-5 landing region, subdividing them into units of Imbrian and Eratosthenian ages. The ages of Em3 and Em4 mare basalts are so close to the end of known lunar mare eruptions ( 1.0 Ga) (Hiesinger et al., 2011, 2003; Stadermann et al., 2018) that they have been proposed as the priority target for the CE-5 mission (Li et al., 2019). Therefore, a comprehensive and detailed geological context and background documentation of the Em3 and Em4 units is indispensable as a foundation to identify the key questions (listed in Tab. 1) related to the CE-5 sample acquisition and subsequent comprehensive laboratory studies. We build on earlier regional studies of the CE-5 landing region by focusing on the young mare basalts, particularly Em4, in terms of regional geomorphology and stratigraphy, lava sources, mineralogy, and chronology. Because earlier studies have reached a wide variety of conclusions about the absolute model ages (AMAs) of the young Em4 basalt unit (Tab. 2), we address several important questions: Are the Em3 and Em4 units actually single lava flow units despite their internal compositional homogeneity at large scales? Do the young mare basalts have minor compositional variations, indicating subunits? Do they have age variations, indicating subunits? Where do the young mare basalts come from and what is their relationship to the longest lunar sinuous rille, Rima Sharp? Where are the youngest mare flows? To address these questions, we present a detailed analysis of the young mare basalts in the CE-5 landing region, focusing on Em4, the most prominent young mare unit in the region.

\section{Young Mare Basalts in the Rümker Region}

\subsection{Regional Setting}

Most of the Em4 mare basalt unit buries the projected Imbrium basin outer ring (Neumann et al., 2015; Spudis et al., 1988) (Fig. 1CDE). The Imbrium basin has undergone significant mare basalt filling beginning shortly after its formation (Hiesinger et al., 2011), a load which contributed significantly to the large central Imbrium mascon (Neumann et al., 2015). Much smaller mass anomalies are found in OP and around Em4 (Chisenga et al., 2020; Deutsch et al., 2019; Evans et al., 2016) (Fig. 2CD). These are generally circular (quasi-circular mass anomalies; QCMAs) and may be related to old impact craters filled with basalt or to volcanic complexes (Evans et al., 2016). Chisenga et al. (2020) identified QCMAs 4 and 5 (red circles, Fig. 2CD) in the east of Em4 that have densities $>3000 \mathrm{~kg} / \mathrm{m}^{3}$, with a depth between 5-25 km and proposed that QCMA5 is one of the sources of the Em4 mare basalts, because of its high density at a depth of $2 \mathrm{~km}$. However, shallow gravity anomalies may have multiple sources (sills, dike swarms, filled buried craters, and the uplifted floors of floor-fractured craters; Deutsch et al., 2019).

\subsection{Topography, Stratigraphy \& Geomorphology 2.2.1 Topography}

Topographic analysis was undertaken utilizing SLDEM2015 data $(\sim 60 \mathrm{~m} /$ pixel; Barker et al., 2016). The Em4 lava plain unit covers an area of $\sim 37,000 \mathrm{~km}^{2}$ to the east of Mons Rümker and west of Montes Jura, the rim of the Iridum basin (Fig. 2A). Over 99\% of the unit lies between $-2400 \mathrm{~m}$ and $-2700 \mathrm{~m}$ in elevation, with a mean elevation of $-2530 \mathrm{~m}$ and a 
mean slope of $0.9^{\circ}$ (Fig. 2B; a baseline length of $\sim 180 \mathrm{~m}$ ). The slope over $95 \%$ of the Em4 unit area is $\left\langle 2^{\circ}\right.$; slopes $>3^{\circ}$ are mostly related to local impact craters. The elevation in Em4 decreases 50 to $100 \mathrm{~m}$ from west to east (Fig. 3A); variations are largely controlled by wrinkle ridges, locally rising up to $200 \mathrm{~m}$ above the regional mare surface. The largest wrinkle ridge system, located western Em4 (white dashed line, Fig. 2A), is asymmetrical with a wider, gently-sloped western side and a steep-sloped eastern side (Fig. 3A).

\subsubsection{Estimation of Mare Thickness and Volume}

The thickness and volume of individual mare basalt units provide information that can be used to assess the generation, ascent, and eruption of magma (Head and Wilson, 2017; Wilson and Head, 2017). We use the inferred excavation depth of craters to assess the thickness of Em4 and to derive its volume (Note S1).

Based on this approach, we find that the average upper thickness limit of all Em4 mare basalts is $62.7 \mathrm{~m}$ and the average lower limit thickness is $39.1 \mathrm{~m}$. The average of the upper and lower limits $(50.9 \mathrm{~m})$ is then regarded as the mean mare thickness of Em4. Then the Em4 mare thickness is interpreted to be between $\sim 39 \mathrm{~m}$ to $\sim 63 \mathrm{~m}$, with a mean value of $\sim 51 \mathrm{~m}$. No systematic differences in mare thickness are recognized in different subunits (Fig. 3B). The estimated mare thickness ( $\sim 39$ to $\sim 63 \mathrm{~m}$ ) matches well with the individual lava flow thicknesses measured by Hiesinger et al. (2002) in Oceanus Procellarum (32 m to $51 \mathrm{~m}$ ) and Morota et al. (2011) for young mare basalts $(20 \mathrm{~m}$ to $60 \mathrm{~m}$ ) using the crater size-frequency distribution technique.

The unit volume is then calculated by multiplying the area of Em4 $\left(37,240 \mathrm{~km}^{2}\right)$ by the mare thickness, yielding a volume range of $1,450-2,350 \mathrm{~km}^{3}$, with a mean value of 1,900 $\mathrm{km}^{3}$. These values lie within the upper and lower limits of individual lunar lava flows calculated by Hiesinger et al. $(2011,2003)$ and are greater than the $10^{2}-10^{3} \mathrm{~km}^{3}$ volume estimated for typical mare basalt eruptions from dike emplacement theory and observations (Head and Wilson, 2017; Wilson and Head, 2017), possibly suggesting that Em4 might have been formed by multiple eruptions.

\subsubsection{Regolith Thickness}

Em4 regolith thickness in the CE-5 landing region has been estimated using the crater morphology method (Qian et al., 2020) (increasing regolith thickness from simple, flatbottomed, central mound, to concentric craters). Qian et al. (2020) found that the Em4 average regolith thickness is $\sim 7 \mathrm{~m}$ (standard deviation, $1.7 \mathrm{~m}$ ); >99\% of Em4 has a regolith thickness $>2 \mathrm{~m}$ (the CE-5 core length). As determined by Qian et al. (2020), regolith in the northern part of Em4 is thicker than the southern part; the southeastern part of Em4 has the thinnest regolith, and regolith thickness is expected to vary locally due to stochastic impact events.

\subsection{Morphology \\ 2.3.1 Kipukas}

Kipukas, which are remnant exposures of pre-existing terrain flooded and embayed by mare basalts consist of 1) highlands, several of which lie on the projected location of the 
Imbrium basin outer ring (orange line, Fig. 2A; Spudis et al., 1988); 2) ghost craters (often with kipukas; Fig. 4B); and 3) the Mairan domes, which are erupted silicic volcanic material (Glotch et al., 2011), including Mairan NW, T, Middle and South Domes (Fig. 1A; Fig. 4 DEF). Only Mairan NW Dome, $\sim 3 \mathrm{~km}$ in diameter and $~ 200$ in height (Fig. 4F), is located within the CE-5 landing region and is distinct from and older than the surrounding mare. Wrinkle ridges commonly trend around kipukas (Fig. 4C), indicating a younger age.

\subsubsection{Volcanic Morphologic Features}

Multiple remote sensing datasets, including Kaguya Terrain Camera (TC) Morning Map and Multiband Imager (MI) compositional data, have been used to search for possible Em4 morphological features (see Section 2.4 and 2.5 for more details). The surface morphology of the Em4 unit (Fig. 2A) shows no evidence for individual topographically distinctive lava flow fronts within the unit, and no source vents or related features (e.g., linear rilles, fissures, cones, domes, etc.; Head and Wilson, 2017) were detected. Nor was evidence for extensive pyroclastic deposits within the unit observed. In addition, no other distinctive mareemplacement-associated features were found within the unit, such as Irregular Mare Patches (Braden et al., 2014) or Ring Moat Domes Structures (e.g., F. Zhang et al., 2020).

\subsubsection{Sinuous Rilles}

Although no specific evidence for a source vent within the Em4 units was found, we examined the margins and vicinity of the unit to search for other candidate sources, particularly Rima Sharp, located along the eastern margin of Em4 and identified in the (Hurwitz et al., 2013) global census of sinuous rilles as the longest sinuous rille on the Moon $(\sim 566 \mathrm{~km})$. Our detailed analysis shows that Rima Sharp consists of at least three rilles, (Rimae Mairan, Sharp, and Louville, Fig. 1A); all of them are independent sinuous rilles and are not branches of Rima Sharp. Direct evidence of the presence of the three different sinuous rilles is the identification of their source depressions at the proximal end of each rille channel (Fig. 4GHI).

Rima Mairan originates from the South Vent, characterized by two linear troughs $(\sim 4 \mathrm{~km}$ and $\sim 3 \mathrm{~km}$ long) (Fig. 4G) and extends to the north. It is $\sim 154 \mathrm{~km}$ long, with an average width and depth of $\sim 489 \mathrm{~m}$ and $\sim 45 \mathrm{~m}$, respectively, based on SLDEM2015 and TC Morning Map. Rima Sharp originates from the North Vent, outside Em4 (Fig. 4H), and extends south into Em4. The North Vent is characterized by a $3 \mathrm{~km}$ long depression, adjacent to another large linear depression (green dashed line), potentially the surface expression of the top of a dike. Rima Sharp is $\sim 312 \mathrm{~km}$ long, with an average width and depth of $\sim 926 \mathrm{~m}$ and $\sim 71 \mathrm{~m}$, respectively. Rima Louville is the smallest sinuous rille of the three (Fig. 4I), originating from an irregular depression (diameter $\sim 1 \mathrm{~km}$; depth $\sim 50 \mathrm{~m}$ ).

All three sinuous rilles flow toward, and terminate within, the eastern interior of Em4 (Fig. 2A). Along their flow directions, their width and depth decrease dramatically. About $\sim 65 \mathrm{~km}$ south of its source, Rima Louville, the smallest of the three, underwent rille capture with Rima Sharp. The two major rilles (Sharp and Mairan) enter the Em4 unit from different directions and appear to shallow and join in the middle of the eastern part of Em4 (Fig. 2A). Although lavas forming Em4 could have erupted through now-buried, dike-fed fissure vents, or from a nearby shallow reservoir (Chisenga et al., 2020), the three separate sinuous rilles 
leading into Em4 are the most obvious candidates for sources.

\subsection{Composition}

Hiesinger et al. (2011, 2003) and Qian et al. (2018) defined Em4 (P58) as a single geological unit because it is distinct from adjacent units and appears compositionally homogeneous at a large scale. In this analysis, we examined additional compositional details, assessing the possibility of subtle variations that might indicate the presence of subunits. In order to pinpoint specific variations and to perform a systematic chronology study (Section 2.5), we subdivided Em4 into fifty-two $1^{\circ} \times 1^{\circ}$ geographic subunits (Fig. S1).

Mare basalts are the dominant rock type in Em4 (Fig. 1), except for the highland kipukas (Fig. 4ABC) and the Mairan dome materials (Fig. 4DEF). The Em4 mare basalts have a deep purple-blue hue in Kaguya MI color composite map (Red: $750 \mathrm{~nm} / 415 \mathrm{~nm}$, Green: 750 nm/950 nm, Blue: 415 nm/750 nm; Fig. 5A), suggesting a high titanium content. Color variations are minor, with the exception of 1) large craters that penetrated through the topmost unit (Em4) and excavated low-Ti Imbrian-aged basalts, 2) small craters excavating fresh, immature materials (light blue), 3) clusters of secondary craters and associated ray material, and 4) areas contaminated by proximity to highlands (purple-red).

We used the Lunar Reconnaissance Orbiter Wide Angle Camera $\mathrm{TiO}_{2}$ abundance map (Sato et al., 2017; <0.5 wt\% accuracy) and Kaguya MI FeO abundance map (Lemelin et al., 2015; <1 wt \% accuracy) to evaluate the abundance and variation of these two key oxides (Fig. 5CD). The mean $\mathrm{TiO}_{2}$ content of $\mathrm{Em} 4$ is $6 \mathrm{wt} \% ; 50.4 \%$ of $\mathrm{Em} 4$ has $\mathrm{TiO}_{2}$ contents $>6$ wt $\%$, belonging to high-Ti mare basalts (Neal and Taylor, 1992); 48.3\% consist of low-Ti basalts (1-6 wt\%), however, some low-Ti materials are distal ejecta from low-Ti/Fe basement rocks (red lines, Fig. 5C), especially by Aristarchus, Harpalus, and Sharp B craters (Qian et al., 2018). FeO abundance correlates positively with $\mathrm{TiO}_{2}$ abundance, suggesting the presence of ilmenite. The mean $\mathrm{FeO}$ content of $\mathrm{Em} 4$ is $17 \mathrm{wt} \%$; $78.4 \%$ of Em4 has a $\mathrm{FeO}$ content of 16-18 wt\%, and the iron-poor rays are mostly related to distal ejecta (red lines, Fig. 5D). The eastern part of Em4 near the Mairan domes and in southwest Em4 has the highest $\mathrm{TiO}_{2}$ and $\mathrm{FeO}$ abundance.

Mineral assemblages characteristic of Em4 are also informative and quantitatively analyzed. We produced an Integrated Band Depth (IBD) color composite map using Moon Mineralogy Mapper ( $\mathrm{M}^{3}$ ) OP2C data (Notes S2 and S3) (Pieters et al., 2009). Em4 displays purple-green hues, indicating the presence of abundant pyroxenes with diagnostic 1000 and $2000 \mathrm{~nm}$ absorptions, and minor OLV with a broader $1000 \mathrm{~nm}$ absorption (Cloutis et al., 1986). The mare basalts (Fig. 5A) between Em4 and Mons Rümker (i.e., Em3) and south of Em4 (i.e., P40) are redder and more purple than all the other units, indicating OLV enrichment. The Em4 mare basalts appear relatively OLV-poor compared with typical high-Ti OLV-rich young mare basalts (e.g., Em3, P40) (e.g., Staid et al., 2011), but still contain more OLV than the older Imbrian-aged mare basalts.

$\mathrm{M}^{3}$ spectra of 510 small fresh craters (10 in each subunit, shown by red dots (Fig. S1), were extracted to study mineralogy in more detail (Note S2, Fig. S2 \& S3). Only small fresh craters were selected because larger craters may have excavated into the underlying low-Ti basalts (Qian et al., 2018) and older craters may have experienced significant space weathering, obscuring their primary mineralogy. Nearly all of the spectra are characterized by 
two absorptions centered at $\sim 1000 \mathrm{~nm}$ and $\sim 2200 \mathrm{~nm}$, indicating the existence of pyroxene. Clinopyroxene (CPX) is more abundant than orthopyroxene (OPX), because the spectra have a longer wavelength Band II absorption ( $2200 \mathrm{~nm}$ ) (Cloutis et al., 1986). OLV is difficult to evaluate directly from spectra because its relatively weak $1000 \mathrm{~nm}$ feature is easily masked by pyroxene (Cloutis et al., 1986); plagioclase (PLG) is also difficult to evaluate due to a lack of clear absorptions.

The absolute mineral abundances of CPX, OPX, OLV, and PLG (Fig. 5F-I) of Em4 have been quantitatively evaluated using Lemelin et al. (2015)'s global mineral abundance data, which were produced based on Kaguya MI data. According to this dataset, PLG (mean 41 wt $\%$ ) and CPX (mean $30 \mathrm{wt} \%$ ) are two dominant mineral types, followed by OPX (mean 16 $\mathrm{wt} \%$ ) and OLV (mean $13 \mathrm{wt} \%$ ). There is $~ 50 \%$ more CPX than OPX in Em4. The Em4 OLV abundance is lower than that of the other young high-Ti mare basalts in the PKT (e.g., Staid et al., 2011), supporting the analysis of the IBD color composite map. The variations of mafic minerals in Em4 are minor and random, lacking clear regions of concentration (Fig. 5F-I); however there is a slight trend that suggests that the eastern part of Em4 has lower CPX but higher OPX than in the west of Em4. There are two kinds of locations where PLG abundance are elevated, 1) regions adjacent to the highlands where PLG accumulated through lateral transport and mixing; 2) secondary ejecta regions where PLG was delivered by distant impacts. In addition, the ilmenite abundance is difficult to calculate through spectra because it has no clear absorptions, therefore it is not included here. However, the $\mathrm{TiO}_{2}$ abundance is good indicator of ilmenite as it is the major carrier of $\mathrm{TiO}_{2}$.

\subsection{Chronology}

The Em4 unit has been dated by many researchers using impact crater size-frequency distribution (CSFD) methods, with the results often interpreted with different chronology and production functions (Giguere et al., 2020; Hiesinger et al., 2003; Jia et al., 2020; Morota et al., 2011; Qian et al., 2018; Wu et al., 2018), and a wide range of AMAs have been reported, ranging from $\sim 1.2-3.3 \mathrm{Ga}$ (Tab. 2; Fig. 6B).

Recent studies of the mare basalts just south of the Aristarchus Plateau (Stadermann et al., 2018) found that the definition of crater counting areas plays a critical role in determining AMAs, even if they are in the same compositionally homogeneous unit. Different AMAs within a compositionally homogeneous unit could be attributed to 1) repeated eruptions of similar composition, separated in time (e.g., Hiesinger et al., 2003, 2011); or 2) the shortcomings of the CSFD technique itself when dating young or small planetary surfaces (Williams et al., 2018). On the other hand, as mentioned in Section 2.4, although the compositions of the Em4 mare basalts are essentially identical on a regional scale, minor variations exist at local scales (e.g., some local enrichment of $\mathrm{TiO}_{2}$ and $\mathrm{FeO}$ ). Thus, we investigate four questions: 1) What is the AMA for the Em4 unit as a whole? 2) What is the AMA-frequency distribution for a sample of smaller subareas? 3) Do any AMA variations within Em4 show regional trends that might correlate with composition or geologic features?

4) Is there any preliminary evidence for more than one eruption for Em4 basalts?

To address these questions, we divided the Em4 unit into fifty-two $1^{\circ} \times 1^{\circ}$ subunits (Fig. S1). The diameters of primary craters larger than $100 \mathrm{~m}$ were measured using the Kaguya TC Morning Map ( 10 m/pixel, right-to-left low-angle solar illumination; Haruyama 
et al., 2008). Areas with abundant secondary craters or covered by large volumes of crater ejecta were excluded (e.g., Mairan G crater, Rümker H crater). CraterTools was used to measure crater locations and diameters (Kneissl et al., 2011). In total, we counted 123,385 craters $>100 \mathrm{~m}$ in diameter. Craterstats was used to analyze the size-frequency distributions (Michael and Neukum, 2010). We use the lunar chronology function and production function of Neukum et al. (2001). Finally, the AMAs and uncertainties are derived using Poisson timing analysis (Michael et al., 2016), and the results are shown in Fig. 6.

We find an absolute model age of the entire Em4 unit of $1.53_{-0.027}^{+0.027} \mathrm{Ga}$ (Fig. 6C, shown as R plot), which we regard as the average age of Em4. The AMA frequency distribution resulting from subdividing Em4 into fifty-two individual $1^{\circ} \times 1^{\circ}$ areas ranges from 1.1 to $2.9 \mathrm{Ga}$, has a peak frequency at $1.5 \mathrm{Ga}$, a mean at $1.68 \mathrm{Ga}$ and a median at $1.6 \mathrm{Ga}$ (Fig. 6D). For $1^{\circ} \times 1^{\circ}$ measurement, the older Em4 subunits are located near its northern and southwestern geological boundary. The youngest mare basalts are in the northwest, northeast, and south of Em4. Some variations within Em4 may be due to concentrations of secondary craters (see red lines in Fig. 5CD).

\section{Discussion}

\subsection{CSFD Model Ages}

\subsubsection{Comparison with Other Studies}

Previous workers measured different AMAs (Fig. 6B; Tab.2) for the high-Ti mare basalt unit (Em4/P58) (Giguere et al., 2020; Hiesinger et al., 2003; Jia et al., 2020; Morota et al., 2011; Qian et al., 2018; Wu et al., 2018). In an ongoing study, Giguere et al. (2020) examined the eastern part of Em4 (P58) adjacent to Mairan T dome and determined the ages of 3.05 and $3.33 \mathrm{Ga}$. These ages are consistent with the superposition of the mare basalts on the $\sim 3.75$ Ga old dome materials (Glotch et al., 2011), but are older than the age determined by Hiesinger et al. (2003; $1.33 \mathrm{Ga}$ ). Morota et al. (2011; red polygons, Fig. 6B) note in their analysis of Em4 (P58) that there was a resurfacing event: an underlying mare basalt with an AMA of $3.46_{-0.44}^{+0.11}$ Ga was covered by subsequent mare basalt, with a thickness of $20-60 \mathrm{~m}$ and an AMA of $1.91_{-0.11}^{+0.11} \mathrm{Ga}$. Indeed, the surrounding basalt units identified by Hiesinger et al. (2003) generally have ages of 3.4-3.7 Ga, but units to the south also exhibit younger resurfacing ages approaching $2 \mathrm{Ga}$. These observations, plus the relatively thin estimated basalt thickness suggest that Em4/P58 is a thin unit emplaced on older Imbrian basalts.

In another analysis, Jia et al. (2020) counted all craters larger than $200 \mathrm{~m}$ in the CE-5 landing region $\left(41-45^{\circ} \mathrm{N}, 49-69^{\circ} \mathrm{W}\right)$ using Lunar Reconnaissance Orbiter Camera-Narrow Angle Camera (LROC-NAC) images, giving an AMA of $2.07 \mathrm{Ga}$. However, their counting area (Fig. 6B, gray dashed polygon; Fig. S5 in Jia et al. (2020)) appears to involve a significant number of secondaries, in particular in the southeast of the CE-5 landing region, as shown by their crater density maps (Fig. 3 in Jia et al., 2020). In our study, we completely eliminated these regions (Fig. 6B, orange dashed polygon) to acquire CSFDs that are easier to interpret.

Hiesinger et al. (2011, 2003), Qian et al. (2018), Wu et al. (2018), and the present study all derive young ages for the Em4 (P58) unit ( $\leq 1.6 \mathrm{Ga})$. Hiesinger et al. $(2011,2003)$ dated the northeast part of Em4/P58 using Lunar Orbiter IV images (green polygon, Fig. 6B), and derived an age of $1.33 \mathrm{Ga}$ ), while Qian et al. (2018) derived an age of 1.21 Ga using Kaguya 
TC Morning Map images in the northwest part of Em4 (blue polygon, Fig. 6B). Their results agree well with our study; we find that subunits in the northeast, northwest, and south have the youngest ages across the Em4 unit (Section 2.5).

In order to assess the use of different chronologies and fitting parameters (or diameters) between the different studies, we used the available data sets from Wu et al. (2018) and the present study to examine potential differences in the crater and age measurements. Wu et al. (2018) mapped all the craters larger than $100 \mathrm{~m}$, applying a machine learning approach based on LROC-NAC images. Their Em4 AMA $\left(1.49_{-0.17}^{+0.17} \mathrm{Ga}\right)$ is slightly younger than our newly determined age $\left(1.53_{-0.027}^{+0.027} \mathrm{Ga}\right)$, although within errors. They focused on the middle part of the CE-5 landing region, which means their crater counting area (purple polygon, Fig. 6B) is much smaller than the Em4 unit. For further comparison, we compiled extra CSFD plots based on Wu et al. (2018)'s original crater counting files to our crater counting areas (Subunit 10, 11, 18, 19, 26, and 27), as shown in Fig. S4. The model ages of subunits using Wu et al. (2018)'s original data agree well with our research (Tab. 2). However, our ages are slightly older than ages using their data, although within error of each other for each pair. We find that many of the crater bins from the Wu et al. (2018) dataset do not correspond well with the lunar production function, which may cause additional uncertainties when fitting the AMAs (Fig. S4). There is a deficiency of smaller craters in the automatically-counted datasets (Wu et al., 2018) compared to our manually-counted results (Fig. S4), possibly due to reduced machine recognition of heavily degraded craters without sharp rims. However human recognition does not have this problem; therefore our ages are slightly older because we counted more degraded craters.

The uncertainties of the crater counting method have been discussed in Note S4. The relatively large crater counting area $\left(\sim 568 \mathrm{~km}^{2}\right)$ and flat and homogeneous surface make the crater counting results more robust. Although Fig. S5 shows that the AMAs of each subunit have some level of uncertainty, nonetheless, the younger and older subunits can be easily separated without overlap. Most of the subunits have AMAs that cluster around $1.5 \mathrm{Ga}$, which is the peak of the age and occupied area histogram (Fig. 6D), and close to the age of the Em4 unit as a whole. In addition, comparing with Wu et al. (2018) further underlines the robustness of our study.

Based on these comparisons, we conclude that the mean AMA of the Em4 unit is approximately $1.53 \mathbf{~ G a}$, but that there is evidence for internal age variability over a range of up to several hundred million years.

\subsubsection{Model Age \& Composition}

The composition of lunar mare basalts has evolved through geological time at both local and global scales, providing information on the nature of mantle source regions (Hiesinger et al., 2011; Morota et al., 2011; Staid et al., 2011). For example, the young lunar mare basalts in Oceanus Procellarum and Mare Imbrium tend to be richer in titanium and OLV with decreasing ages (e.g., Staid et al., 2011). To identify possible trends within the Em4 unit, we compared the mean values of the $\mathrm{AMAs}$ and $\mathrm{TiO}_{2}$ abundance, $\mathrm{FeO}$ abundance, PLG, CPX, OPX, and OLV volumes for each $1^{\circ} \times 1^{\circ}$ subunit (Fig. 7). The center points of the horizontal lines represent AMAs, while the error bars are from Poisson timing analyses. The center points of vertical lines represent the mean value of composition in each subunit, while the 
error bars represent one standard derivation.

We find that the $\mathrm{TiO}_{2}$ abundance of Em4 increases from $\sim 4.5 \mathrm{wt} \%$ before $2.3 \mathrm{Ga}$ to $\sim 7$ $\mathrm{wt} \%$ at $1.5 \mathrm{Ga}$ and decreases to $6 \mathrm{wt} \%$ at $1.0 \mathrm{Ga}$; most of the subunits have a $\mathrm{TiO}_{2}$ abundance between 5.5-6.5 wt \% . The FeO abundance has similar trends; it increases from $16 \mathrm{wt} \%$ before $2.3 \mathrm{Ga}$ to $17.5 \mathrm{wt} \%$ at $1.5 \mathrm{Ga}$, and decreases to $\sim 17 \mathrm{wt} \%$ at $1.1 \mathrm{Ga}$. The synchronous change of $\mathrm{TiO}_{2}$ and $\mathrm{FeO}$ supports the presence of ilmenite in the Em4 unit, and its increase from $2.3 \mathrm{Ga}$, with a peak at $1.4-1.5 \mathrm{Ga}$. The highest $\mathrm{TiO}_{2}$ and $\mathrm{FeO}$ abundances also correspond to the 1.4-1.5 Ga peak in the frequency distribution of the Em4 subunit ages (Fig. 6D), meaning that basalts of this age are the most areally extensive in the Em4 unit. In addition, the variation of $\mathrm{TiO}_{2}$ and $\mathrm{FeO}$ values are readily seen in the compositional maps (Fig. 5).

In contrast to potential trends in $\mathrm{TiO}_{2}$ and $\mathrm{FeO}$ contents, the temporal variations of mafic minerals (CPX, OPX, and OLV) and PLG are nearly imperceptible. These four minerals have nearly identical abundances between $1.0 \mathrm{Ga}$ and $3.0 \mathrm{Ga}(\sim 30 \mathrm{wt} \%, \sim 15 \mathrm{wt} \%, \sim 10 \mathrm{wt} \%$, and $\sim 45 \mathrm{wt} \%$, respectively). In summary, our data suggest that the mineralogical evolution of the Em4 basalt unit shows 1) some evolution of ilmenite ( $\mathrm{TiO}_{2}$ and $\left.\mathrm{FeO}\right)$, but 2) that the major mafic mineral abundances (CPX, OPX, and OLV) remain nearly unchanged.

\subsection{Source Vents}

We found no surface morphological evidence for source vents within the Em4 unit (Section 2.3.2). Chisenga et al. (2020) interpreted the shallow gravity anomaly QCMA5 (Fig. 2CD) as an exceedingly shallow magma reservoir that was the preferred source for the Em4 unit. However, the difficulty in general of producing shallow lunar magma reservoirs (Head and Wilson, 2017; Wilson and Head, 2017) disfavors their presence in the upper part of the crust. The numerous other small circular gravity anomalies in Oceanus Procellarum (black arrows, Fig. 1DE) and the clear correlation of many of these with lava-flooded buried craters (Deutsch et al., 2019; Evans et al., 2016) indicates that QCMA5 is likely to be a lava-filled impact crater.

Mons Rümker may be the source of the Imbrian-aged low-Ti mare basalts in the western part of CE-5 landing region (Zhao et al., 2017; Qian et al., 2018). However, because Mons Rümker has dramatically different ages (Imbrian-aged vs Eratosthenian-aged) and composition (low-Ti vs high-Ti) compared to Em4, it is not a source of lavas to Em4 except for the low-Ti mare basalts buried by Em4. Currently, the most likely source vents for the Em4 lavas are the proximal depressions of the three sinuous rilles (Rima Sharp, Rima Mairan, and Rima Louville) that start outside, but flow into Em4. The formation of these sinuous rilles implies the influx of a huge quantity of lava (Wilson and Head, 2017) into the Em4 region. The absence of extensive pyroclastic deposits at the rille source vents (Fig. 4GHI), together with the small vent diameters, suggests that the volatile contents of the erupted lavas were relatively low (Wilson and Head, 2017).

\subsection{Where Are the Youngest Mare Basalts?}

No lunar mare basaltic samples younger than 2.9 Ga (NWA773, NWA032) have yet been acquired (Borg et al., 2004); therefore, the sampling of young mare basalts has great significance for our understanding of lunar impact history and thermal evolution (National 
Research Council, 2007). Samples from the young mare basalts of the Em4 unit can be used to calibrate the lunar chronology function to fill the gap between 1.0 and $3.0 \mathrm{Ga}$, improving a critical tool for dating unsampled surfaces on the Moon, as well as on other planetary surfaces using the crater counting technique (van der Bogert and Hiesinger, 2020). The Em4 mare basalts can also be used to constrain the duration of mare volcanism and the nature and evolution of mantle sources to understand lunar thermal and magmatic history (Qian et al., 2018). Therefore, it is important to locate potentially young mare flows in the Em4 unit, especially the youngest ones, to maximize the mission outcome.

Our analysis of candidate Em4 source vents and the initial analysis of age distributions within Em4 subunits suggest that the Em4 unit is likely to consist of multiple eruption events, separated in time (Fig. 6D) and space (Fig. 6A). We identified three areas that are candidates for the youngest mare regions within Em4 (in the northwest, northeast, and south; orange circles, Fig. 6A). The northwest candidates have limited distribution, close to the western boundary of Em4. The northeast candidates occur along the eastern mare/highland boundary. Candidates in the south have the largest areal distribution; their northern part is covered by ejecta of Mairan G crater, which may have resurfaced the mare surface to some extent. However, we have eliminated the continuous ejecta in our crater counting areas. Therefore, we regard the southern youngest mare basalts as the best candidate for the youngest subunit in the Em4 region. These three candidate youngest mare regions in Em4 are all valuable sampling sites to assess the range of youngest mare basalts on the Moon.

Regolith samples from any of these youngest mare regions are also very likely to contain older Imbrian-aged mare basalts from the west (e.g., Harding crater), highland materials from the east (e.g., Sharp B crater), and other younger mare basalts from the south (e.g., Aristarchus crater). In addition, CE-5 will very likely sample mare basalts not only with a mean age of $\sim 1.53 \mathrm{Ga}$, but also with a spectrum of ages, delivered by impacts but including younger ones and older ones. The age maps presented here are thus of potential use to trace such samples back to their original locations.

\subsection{The Role of the Procellarum KREEP Terrane in the Generation of Mare Basalts}

Jolliff et al. (2000) utilized global Th and FeO distribution data to divide the Moon into three global terrane types: Procellarum-KREEP (PKT), Feldspathic Highland (FHT), and South Pole-Aitken (SPAT). They pointed out that the PKT, while comprising only $\sim 16 \%$ of the surface, contained 1) the highest Th abundances (perhaps as much as $40 \%$ of global Th), 2 ) the majority of the area covered by maria $(>60 \%)$, and 3 ) the region of the youngest mare basalts. They proposed that the high-Th content of the PKT could be a major factor in generating and sustaining mare basalt volcanism there. Indeed, Wieczorek and Phillips (2000) proposed a model that linked the elevated PKT Th content with the thermal structure of PKT crust and mantle, and generation of mare basalts. Although this idea is not without controversy (Hess and Parmentier, 2001), many workers have supported a significant role for the elevated Th-content of the PKT in the thermal and volcanic history of the region (e.g., Ziethe et al., 2009). Haskin et al. (2000) proposed that the elevated Th content of the regolith overlying the mare units within the PKT (Fig. 5E) was direct evidence for the role of the PKT in the generation of the mare basalts there, representing regolith derived from the underlying Th-rich basalts. More recently, J. Zhang et al. (2020) have proposed on the basis 
of PKT stratigraphy that the distribution of the enhanced Th-content in the PKT is primarily related to a history of impact cratering excavation and redistribution of KREEP/Th-rich materials, and is not an inherent and unusual property of the initial PKT crust and mantle.

Em4 is located in the northwestern part of the Procellarum KREEP Terrane and displays an elevated Th content (Fig. 5E) compared with maria well-outside the PKT. According to the interpretations of Jolliff et al. (2000), Haskin et al. (2000), and Wieczorek and Phillips (2000), the elevated Th values should represent an intrinsic property of the mare basalts. In contrast, hypotheses such as those of Hess and Parmentier (2001) and J. Zhang et al. (2020) predict that the basalts are generated at greater subcrustal depths in the mantle and should be uncontaminated by the high Th-content of the PKT. Indeed J. Zhang et al. (2020) suggest that the elevated Th-content of the mare regolith is due to vertical and lateral mixing by high-Th content highlands.

Thus, the mantle source region, the Th-abundance, and the mode of emplacement of the Procellarum mare basalts (the Imbrian-aged low-Ti basalts below and the overlying Eratosthenian-aged high-Ti basalts) are three additional key questions that need to be assessed and that can be addressed with the analysis of CE-5 returned samples (Tab. 1), specifically measurements of the Th-content of mare basalts fragments and comparison with the Th-content of the mare and highland soil fragments.

\section{Conclusions}

1) The CE-5 landing region is within the distinctive northern Oceanus Procellarum region, which a) lies within the unique PKT, b) has the highest concentration of red spots, c) contains the greatest mare basalt age range on the Moon, d) is the site of the youngest mare basalts, e) shows a diversity of smaller gravity anomalies, and f) is characterized by a distinct polygonal gravity gradient anomaly.

2) The Em4 unit is in the east of the CE-5 landing region and covers an area of 37,000 $\mathrm{km}^{2}$ with a mean thickness of $\sim 51 \mathrm{~m}$ and has a volume between $\sim 1,450$ and $2,350 \mathrm{~km}^{3} . \sim 7 \mathrm{~m}$ of Th-rich regolith develops on the top of the Em4 mare basalts. Distal materials are mixed with the regolith by impacts, mostly from Aristarchus, Harpalus, and Sharp B craters.

3) Em4 mare basalts have a mean age of $\sim 1.53 \mathrm{Ga}$, with some variations, and the youngest mare basalts are located to the south, northwest, and northeast of $\mathrm{Em} 4$. The $\mathrm{TiO}_{2}$ and $\mathrm{FeO}$ (ilmenite) contents have a slight trend toward decreasing abundance with time. Em4 is the youngest mare unit in the landing region $(\sim 1.53 \mathrm{Ga})$, and is thus a priority target for the CE-5 mission.

4) Em4 mare basalts are a type of high-Ti lunar mare basalt located in the PKT, but not typical of that terrain. CPX is the dominant mafic mineral, followed by OPX and OLV. CPX, OPX, OLV, and PLG values are homogeneous within Em4; the highest ilmenite $\left(\mathrm{TiO}_{2}\right)$ abundances occur in the eastern part of Em4 near the Mairan domes and in southwest Em4.

5) No obvious volcanic source vents within the unit are found that could have contributed to the Em4 mare basalts. We find that Rima Sharp is actually composed of three major rilles (Rima Sharp, Rima Mairan, and Rima Louville); source vents of each rille are located outside Em4, but the rilles enter Em4, and are likely to be among the most important sources for the unit

6) Because of the distinctive characteristics of the Em4 mare basalts, any samples 
returned from Em4 for terrestrial laboratory analysis will address a very wide range of fundamental problems (Tab. 1) regarding the geological and thermal evolution of the Moon. This study provides a fundamental guide for future researchers.

\section{Data Availability}

Data used and derived from this research are uploaded to Mendeley Data (http://dx.doi.org/10.17632/5dnt9h58px.1), including geological boundaries, compositional data, spectra, and crater counting results, etc. 3D density tomography data produced by Chisenga et al. (2020) are from Harvard Dataverse (https://dataverse.harvard.edu/dataset.xhtml?persistentId=doi:10.7910/DVN/HNIIZG). CraterTools and Craterstats are from Freie Universität Berlin (https://www.geo.fuberlin.de/en/geol/fachrichtungen/planet/software/index.html).

\section{Acknowledgments}

The authors especially thank William McKinnon for his conscientious and helpful editorial assistance and two reviewers for their thoughtful suggestions which helped improve the quality and readability of the paper. This research is funded by the National Key R \& D Program of China (2020YFE0202100), the Pre-research Project on Civil Aerospace Technologies of CNSA (D020101, D020205), and National Natural Science Foundation of China (41830214). Yuqi Qian is funded by the China Scholarship Council 201906410015. Carolyn van der Bogert and Harald Hiesinger are funded by the German Aerospace Center (Deutsches Zentrum für Luftund Raumfahrt) project 50OW2001. The authors wish to thank Ralph Milliken for discussions of spectroscopy and Ingrid Daubar for discussions of crater counting techniques.

\section{Reference}

Andrews-Hanna, J.C., Asmar, S.W., Head, J.W., Kiefer, W.S., Konopliv, A.S., Lemoine, F.G., Matsuyama, I., Mazarico, E., McGovern, P.J., Melosh, H.J., Neumann, G.A., Nimmo, F., Phillips, R.J., Smith, D.E., Solomon, S.C., Taylor, G.J., Wieczorek, M.A., Williams, J.G., Zuber, M.T., 2013. Ancient Igneous Intrusions and Early Expansion of the Moon Revealed by GRAIL Gravity Gradiometry. Science (80-. ). 339, 675-678.

Barker, M.K., Mazarico, E., Neumann, G.A., Zuber, M.T., Haruyama, J., Smith, D.E., 2016. A new lunar digital elevation model from the Lunar Orbiter Laser Altimeter and SELENE Terrain Camera. Icarus 273, 346-355. https://doi.org/10.1016/j.icarus.2015.07.039

Borg, L.E., Shearer, C.K., Asmerom, Y., Papike, J.J., 2004. Prolonged KREEP magmatism on the Moon indicated by the youngest dated lunar igneous rock. Nature 432, 209-211. https://doi.org/10.1038/nature03070

Braden, S.E., Stopar, J.D., Robinson, M.S., Lawrence, S.J., van der Bogert, C.H., Hiesinger, H., 2014. Evidence for basaltic volcanism on the Moon within the past 100 million years. Nat. Geosci. 7, 787. https://doi.org/10.1038/ngeo2252

Chisenga, C., Yan, J., Zhao, J., Atekwana, E.A., Steffen, R., 2020. Density Structure of the Rümker Region in the Northern Oceanus Procellarum: Implications for Lunar Volcanism and Landing Site Selection for the Chang'E-5 Mission. J. Geophys. Res. 
Planets 125, e2019JE005978. https://doi.org/10.1029/2019JE005978

Cloutis, E.A., Gaffey, M.J., Jackowski, T.L., Reed, K.L., 1986. Calibrations of phase abundance, composition, and particle size distribution for olivine-orthopyroxene mixtures from reflectance spectra. J. Geophys. Res. Solid Earth 91, 11641-11653. https://doi.org/10.1029/JB091iB11p11641

Deutsch, A.N., Neumann, G.A., Head, J.W., Wilson, L., 2019. GRAIL-identified gravity anomalies in Oceanus Procellarum: Insight into subsurface impact and magmatic structures on the Moon. Icarus 331, 192-208. https://doi.org/https://doi.org/10.1016/j.icarus.2019.05.027

Evans, A.J., Soderblom, J.M., Andrews-Hanna, J.C., Solomon, S.C., Zuber, M.T., 2016. Identification of buried lunar impact craters from GRAIL data and implications for the nearside maria. Geophys. Res. Lett. 43, 2445-2455. https://doi.org/10.1002/2015GL067394

Giguere, T.A., Boyce, J.M., Gillis-Davis, J.J., Stopar, J.D., 2020. Lava Flows in Northeastern Oceanus Procellarum: Morphology, Composition, and Ages, in: 51st Lunar and Planetary Science Conference. Lunar and Planetary Institute, Houston, p. Abstract \#2356.

Glotch, T.D., Hagerty, J.J., Lucey, P.G., Hawke, B.R., Giguere, T.A., Arnold, J.A., Williams, J.-P., Jolliff, B.L., Paige, D.A., 2011. The Mairan domes: Silicic volcanic constructs on the Moon. Geophys. Res. Lett. 38. https://doi.org/10.1029/2011GL049548

Haruyama, J., Matsunaga, T., Ohtake, M., Morota, T., Honda, C., Yokota, Y., Torii, M., Ogawa, Y., 2008. Global lunar-surface mapping experiment using the Lunar Imager/Spectrometer on SELENE. Earth, planets Sp. 60, 243-255. https://doi.org/10.1186/BF03352788

Haskin, L.A., Gillis, J.J., Korotev, R.L., Jolliff, B.L., 2000. The materials of the lunar Procellarum KREEP Terrane: A synthesis of data from geomorphological mapping, remote sensing, and sample analyses. J. Geophys. Res. Planets 105, 20403-20415. https://doi.org/10.1029/1999JE001128

Head, J.W., Wilson, L., 2017. Generation, ascent and eruption of magma on the Moon: New insights into source depths, magma supply, intrusions and effusive/explosive eruptions (Part 2: Predicted emplacement processes and observations). Icarus 283, 176-223. https://doi.org/10.1016/j.icarus.2016.05.031

Hess, P.C., Parmentier, E.M., 2001. Thermal evolution of a thicker KREEP liquid layer. J. Geophys. Res. Planets 106, 28023-28032. https://doi.org/10.1029/2000JE001416

Hiesinger, H., Head, J.W., Wolf, U., Jaumann, R., Neukum, G., 2011. Ages and stratigraphy of lunar mare basalts: A synthesis. Spec. Pap. Geol. Soc. Am. 477, 1-51. https://doi.org/10.1130/2011.2477(01)

Hiesinger, H., Head, J.W., Wolf, U., Jaumann, R., Neukum, G., 2003. Ages and stratigraphy of mare basalts in Oceanus Procellarum, Mare Nubium, mare Cognitum, and Mare Insularum. J. Geophys. Res. E Planets 108, 1-1. https://doi.org/10.1029/2002je001985

Hiesinger, H., Head, J.W., Wolf, U., Jaumann, R., Neukum, G., 2002. Lunar mare basalt flow units: Thicknesses determined from crater size-frequency distributions. Geophys. Res. Lett. 29, 84-89. https://doi.org/10.1029/2002GL014847

Hurwitz, D.M., Head, J.W., Hiesinger, H., 2013. Lunar sinuous rilles: Distribution, 
572

573

574

575

576

577

578

579

580

581

582

583

584

585

586

587

588

589

590

591

592

593

594

595

596

597

598

599

600

601

602

603

604

605

606

607

608

609

610

611

612

613

614

615

characteristics, and implications for their origin. Planet. Space Sci. 79-80, 1-38. https://doi.org/10.1016/j.pss.2012.10.019

Jia, M., Yue, Z., Di, K., Liu, B., Liu, J., Michael, G., 2020. A catalogue of impact craters larger than $200 \mathrm{~m}$ and surface age analysis in the Chang'e-5 landing area. Earth Planet. Sci. Lett. 541, 116272. https://doi.org/10.1016/j.eps1.2020.116272

Jolliff, B.L., Gillis, J.J., Haskin, L.A., Korotev, R.L., Wieczorek, M.A., 2000. Major lunar crustal terranes: Surface expressions and crust-mantle origins. J. Geophys. Res. Planets 105, 4197-4216. https://doi.org/10.1029/1999JE001103

Kneissl, T., van Gasselt, S., Neukum, G., 2011. Map-projection-independent crater sizefrequency determination in GIS environments-New software tool for ArcGIS. Planet. Space Sci. 59, 1243-1254. https://doi.org/https://doi.org/10.1016/j.pss.2010.03.015 Lemelin, M., Lucey Paul, G., Song, E., Taylor, G.J., 2015. Lunar central peak mineralogy and iron content using the Kaguya Multiband Imager: Reassessment of the compositional structure of the lunar crust. J. Geophys. Res. Planets 120, 869-887. https://doi.org/10.1002/2014JE004778

Li, C., Wang, C., Wei, Y., Lin, Y., 2019. China's present and future lunar exploration program. Science (80-. ). 365, 238-239. https://doi.org/10.1126/science.aax9908

Michael, G.G., Kneissl, T., Neesemann, A., 2016. Planetary surface dating from crater sizefrequency distribution measurements: Poisson timing analysis. Icarus 277, 279-285. https://doi.org/https://doi.org/10.1016/j.icarus.2016.05.019

Michael, G.G., Neukum, G., 2010. Planetary surface dating from crater size-frequency distribution measurements: Partial resurfacing events and statistical age uncertainty. Earth Planet. Sci. Lett. 294, 223-229.

https://doi.org/https://doi.org/10.1016/j.epsl.2009.12.041

Morota, T., Haruyama, J., Ohtake, M., Matsunaga, T., Honda, C., Yokota, Y., Kimura, J., Ogawa, Y., Hirata, N., Demura, H., Iwasaki, A., Sugihara, T., Saiki, K., Nakamura, R., Kobayashi, S., Ishihara, Y., Takeda, H., Hiesinger, H., 2011. Timing and characteristics of the latest mare eruption on the Moon. Earth Planet. Sci. Lett. 302, 255-266. https://doi.org/10.1016/j.eps1.2010.12.028

National Research Council, 2007. The Scientific Context for Exploration of the Moon. The National Academies Press, Washington, DC. https://doi.org/10.17226/11954

Neal, C.R., Taylor, L.A., 1992. Petrogenesis of mare basalts: A record of lunar volcanism. Geochim. Cosmochim. Acta 56, 2177-2211. https://doi.org/https://doi.org/10.1016/0016-7037(92)90184-K

Neukum, G., Ivanov, B.A., Hartmann, W.K., 2001. Cratering Records in the Inner Solar System in Relation to the Lunar Reference System, in: Kallenbach, R., Geiss, J., Hartmann, William K (Eds.), Chronology and Evolution of Mars. Springer Netherlands, Dordrecht, pp. 55-86.

Neumann, G.A., Zuber, M.T., Wieczorek, M.A., Head, J.W., Baker, D.M.H., Solomon, S.C., Smith, D.E., Lemoine, F.G., Mazarico, E., Sabaka, T.J., Goossens, S.J., Melosh, H.J., Phillips, R.J., Asmar, S.W., Konopliv, A.S., Williams, J.G., Sori, M.M., Soderblom, J.M., Miljković, K., Andrews-Hanna, J.C., Nimmo, F., Kiefer, W.S., 2015. Lunar impact basins revealed by Gravity Recovery and Interior Laboratory measurements. Sci. Adv. 1. 
616

617

618

619

620

621

622

623

624

625

626

627

628

629

630

631

632

633

634

635

636

637

638

639

640

641

642

643

644

645

646

647

648

649

650

651

652

653

654

655

656

657

658

659
Pei, Z., Wang, Q., Tian, Y., 2015. Technology Roadmap for Chang'e Program. J. Deep Sp. Explor. 2, 99-110. https://doi.org/10.15982/j.issn.2095-7777.2015.02.001

Pieters, C.M., Boardman, J., Buratti, B., Chatterjee, A., Clark, R., Glavich, T., Green, R., Head, J., Isaacson, P., Malaret, E., McCord, T., Mustard, J., Petro, N., Runyon, C., Staid, M., Sunshine, J., Taylor, L., Tompkins, S., Varanasi, P., White, M., 2009. The Moon Mineralogy Mapper (M3) on Chandrayaan-1. Curr. Sci. 96, 500-505.

Qian, Y., Xiao, L., Yin, S., Zhang, M., Zhao, S., Pang, Y., Wang, J., Wang, G., Head, J.W., 2020. The regolith properties of the Chang'e-5 landing region and the ground drilling experiments using lunar regolith simulants. Icarus 337.

https://doi.org/10.1016/j.icarus.2019.113508

Qian, Y.Q., Xiao, L., Zhao, S.Y., Zhao, J.N., Huang, J., Flahaut, J., Martinot, M., Head, J.W., Hiesinger, H., Wang, G.X., 2018. Geology and Scientific Significance of the Rümker Region in Northern Oceanus Procellarum: China's Chang'E-5 Landing Region. J. Geophys. Res. Planets 123. https://doi.org/10.1029/2018JE005595

Sato, H., Robinson, M.S., Lawrence, S.J., Denevi, B.W., Hapke, B., Jolliff, B.L., Hiesinger, H., 2017. Lunar mare $\mathrm{TiO} 2$ abundances estimated from UV/Vis reflectance. Icarus 296, 216-238. https://doi.org/10.1016/j.icarus.2017.06.013

Spudis, P.D., Hawke, B.R., Lucey, P.G., 1988. Materials and formation of the Imbrium basin, in: 18th Lunar and Planetary Science Conference. Texas, Houston, pp. 155-168.

Stadermann, A.C., Zanetti, M.R., Jolliff, B.L., Hiesinger, H., van der Bogert, C.H., Hamilton, C.W., 2018. The age of lunar mare basalts south of the Aristarchus Plateau and effects of secondary craters formed by the Aristarchus event. Icarus 309, 45-60. https://doi.org/10.1016/j.icarus.2018.02.030

Staid, M.I., Pieters, C.M., Besse, S., Boardman, J., Dhingra, D., Green, R., Head, J.W., Isaacson, P., Klima, R., Kramer, G., Mustard, J.M., Runyon, C., Sunshine, J., Taylor, L.A., 2011. The mineralogy of late stage lunar volcanism as observed by the Moon Mineralogy Mapper on Chandrayaan- 1. J. Geophys. Res. Planets 116. https://doi.org/10.1029/2010JE003735@10.1002

van der Bogert, C.H., Hiesinger, H., 2020. Which Samples are Needed for Improved Calibration of the Lunar Cratering Chronology?, in: 51st Lunar and Planetary Science Conference. Lunar and Planetary Institute, The Woodlands, Texas, p. Abstract \#2088.

Whitford-Stark, J.L., Head, J.W., 1980. Stratigraphy of Oceanus Procellarum basalts: Sources and styles of emplacement. J. Geophys. Res. Solid Earth 85, 6579-6609. https://doi.org/10.1029/JB085iB11p06579

Wieczorek, M.A., Neumann, G.A., Nimmo, F., Kiefer, W.S., Taylor, G.J., Melosh, H.J., Phillips, R.J., Solomon, S.C., Andrews-Hanna, J.C., Asmar, S.W., Konopliv, A.S., Lemoine, F.G., Smith, D.E., Watkins, M.M., Williams, J.G., Zuber, M.T., 2013. The Crust of the Moon as Seen by GRAIL. Science (80-. ). 339, 671.

https://doi.org/10.1126/science.1231530

Wieczorek, M.A., Phillips, R.J., 2000. The "Procellarum KREEP Terrane": Implications for mare volcanism and lunar evolution. J. Geophys. Res. Planets 105, 20417-20430. https://doi.org/10.1029/1999JE001092

Williams, J.-P., Bogert Carolyn, H., Pathare Asmin, V., Michael Gregory, G., Kirchoff Michelle, R., Hiesinger, H., 2018. Dating very young planetary surfaces from crater 
statistics: A review of issues and challenges. Meteorit. Planet. Sci. 53, 554-582. https://doi.org/10.1111/maps.12924

Wilson, L., Head, J.W., 2017. Generation, ascent and eruption of magma on the Moon: New insights into source depths, magma supply, intrusions and effusive/explosive eruptions (Part 1: Theory). Icarus 283, 146-175. https://doi.org/10.1016/j.icarus.2015.12.039

Wilson, L., Head, J.W., 2003. Lunar Gruithuisen and Mairan domes: Rheology and mode of emplacement. J. Geophys. Res. Planets 108. https://doi.org/10.1029/2002JE001909

Wu, B., Huang, J., Li, Y., Wang, Y., Peng, J., 2018. Rock Abundance and Crater Density in the Candidate Chang'E-5 Landing Region on the Moon. J. Geophys. Res. Planets 123, 3256-3272. https://doi.org/10.1029/2018JE005820

Zhang, F., Head, J.W., Wöhler, C., Bugiolacchi, R., Wilson, L., Basilevsky, A.T., Grumpe, A., Zou, Y.L., 2020. Ring-Moat Dome Structures (RMDSs) in the Lunar Maria: Statistical, Compositional, and Morphological Characterization and Assessment of Theories of Origin. J. Geophys. Res. Planets 125, e2019JE005967. https://doi.org/https://doi.org/10.1029/2019JE005967

Zhang, J., Liu, J., Head, J.W., 2020. Analysis of Thorium Concentration Anomalies on the Lunar Surface. 51st Lunar Planet. Sci. Conf.

Zhao, J., Xiao, L., Qiao, L., Glotch, T.D., Huang, Q., 2017. The Mons Rümker volcanic complex of the Moon: A candidate landing site for the Chang'E-5 mission. J. Geophys. Res. Planets 122, 1419-1442. https://doi.org/10.1002/2016JE005247

Ziethe, R., Seiferlin, K., Hiesinger, H., 2009. Duration and extent of lunar volcanism: Comparison of 3D convection models to mare basalt ages. Planet. Space Sci. 57, 784796. https://doi.org/10.1016/j.pss.2009.02.002 
Table 1. Key questions for the analysis of the samples returned by CE-5. On the basis of the characteristics and the unique geologic setting of the CE-5 landing region, a series of fundamental questions that can be addressed are listed here.

\begin{tabular}{|c|c|}
\hline Chronology & $\begin{array}{l}\text { 1) What is the absolute age of the majority of Em4? 2) How many separate mare emplacement events } \\
\text { are recognizable in the samples? 3) How does this range of events compare to the observed AMA } \\
\text { variations? 4) What are the implications of the radiometric age characteristics for lunar and planetary } \\
\text { time scales, and the interplanetary flux? 5) Is there any evidence for silica-rich red spots materials, } \\
\text { and if so, what is their age? 6) Are there samples of impact basin ejecta (e.g., Iridum, Imbrium, etc.) } \\
\text { and what are their ages? 7) Is there any evidence of the presence of an ancient Procellarum impact } \\
\text { basin? }\end{array}$ \\
\hline Petrogenesis & $\begin{array}{l}\text { 1) Are the Em4 mare basalts characterized by elevated Th content, as suggested by the remote sensing } \\
\text { data, and thus derived from enhanced melting due to the high Th-content in the PKT Terrane? 2) Are } \\
\text { the Em4 mare basalts characterized by low Th-content more similar to that of Apollo/Luna basalts, } \\
\text { suggesting that they are derived from melting in deeper mantle source regions unassociated with the } \\
\text { PKT terrane? 3) What are the depths of source region melting estimated for the mare basalts? 4) Is } \\
\text { there any evidence for changes in source regions with time? 5) Is there any petrologic evidence for } \\
\text { shallow magma storage and staging? 6) What is the estimated volatile content of the Em4 and related } \\
\text { basalts? Are these consistent with the relatively low contents estimated by the sinuous rille source } \\
\text { regions and the lack of RMDS and IMPs? Is it variable? 7) Is there any evidence of KREEP basalts } \\
\text { and if so, what are their natures and ages? 8) Is there any evidence for Mg-suite rocks, and if so how } \\
\text { do they differ from those in the Apollo/Luna zone? }\end{array}$ \\
\hline Regional Setting & $\begin{array}{l}\text { 1) What is the range of Th content in the returned samples, their provenance, and their ages? 2) Was } \\
\text { the elevated Th content in the PKT important in the generation and emplacement of mare basalts in } \\
\text { the PKT, or are there other potential factors involved in their distribution and duration? 3) What are } \\
\text { the implications of the CE-5 sample analysis and characterization for the nature, structure, and } \\
\text { influence of the Procellarum-KREEP Terrane (PKT)? }\end{array}$ \\
\hline $\begin{array}{c}\text { Geodynamic \& } \\
\text { Thermal } \\
\text { Evolution }\end{array}$ & $\begin{array}{l}\text { 1) Are the Em4 and related mare basalt units magnetized and how do their magnetic characteristics } \\
\text { change with time? 2) Is there evidence to distinguish between the PKT region demagnetized magnetic } \\
\text { anomaly being the site of thermal (PKT-related) or impact demagnetization? 3) Does petrogenetic } \\
\text { evidence support deep sources for the mare basalt magmas related to a thickening lithosphere in later } \\
\text { lunar thermal evolution, or are other explanations required to account for their youth? }\end{array}$ \\
\hline $\begin{array}{c}\text { Regolith } \\
\text { Formation }\end{array}$ & $\begin{array}{l}\text { 1) Where does the Th reside in the regolith? In the mare basalt components, suggesting that the Th is } \\
\text { an inherent part of the basaltic units? Or is it concentrated in the non-mare regolith soils, suggesting } \\
\text { that the Th is transported into the regolith by lateral mixing from the highlands? 2) What is the range } \\
\text { of components in the young Em } 4 \text { unit regolith and how do they compare with the older, more mature } \\
\text { regolith of the Apollo/Luna sites? 3) Is there any evidence of silica-rich red spot contributions, and if } \\
\text { so what is their nature and age? 4) Is there any evidence for mare basalt pyroclastic glass beads (both } \\
\text { quenched and crystallized) and if so, how do they relate to the petrology and age of the sampled mare } \\
\text { basalts? 5) What is the stratigraphy in the CE-5 core? How does it relate to local and regional impact } \\
\text { events, and how does it inform us about young regolith development? 6) On the basis of the } \\
\text { percentage of foreign components in the regolith, how do Em4 regolith processes compare to older, } \\
\text { more mature regolith? 7) Do any exotic non-mare components in the regolith relate to pre-mare craters } \\
\text { and basins in the region? If so, what is their provenance and age? }\end{array}$ \\
\hline
\end{tabular}


688 Table 2. CSFD absolute model ages (Ga) of the Em4 unit from different studies.

\begin{tabular}{|c|c|c|c|c|c|c|}
\hline & \multicolumn{6}{|c|}{ Geologic Units } \\
\hline & $\operatorname{Im} 1$ & $\operatorname{Im} 2$ & $\operatorname{Im} 3$ & Em1 & Em3 & Em4 \\
\hline $\begin{array}{l}\text { Hiesinger et al. } \\
(2003,2011)\end{array}$ & 3.47 & 3.44 & 3.40 & & & 1.33 \\
\hline $\begin{array}{l}\text { Morota et al. } \\
\text { (2011) }\end{array}$ & / & l & l & l & l & $\begin{array}{l}1.91_{-0.11}^{+0.11} \text { (Model A) } \\
2.20_{-0.13}^{+0.13} \text { (Model B) }\end{array}$ \\
\hline $\begin{array}{l}\text { Qian et al. } \\
(2018)\end{array}$ & $3.42_{-0.02}^{+0.02}$ & $3.39_{-0.02}^{+0.02}$ & $3.16_{-0.09}^{+0.06}$ & $2.30_{-0.10}^{+0.10}$ & $1.51_{-0.07}^{+0.07}$ & $1.21_{-0.03}^{+0.03}$ \\
\hline Wu et al. (2018) & $3.48_{-0.04}^{+0.03}$ & $3.47_{-0.02}^{+0.02}$ & & $2.03_{-0.33}^{+0.33}$ & $2.06_{-0.24}^{+0.24}$ & $1.49_{-0.17}^{+0.17}$ \\
\hline $\begin{array}{l}\text { T. A. Giguere et } \\
\text { al. }(2020)\end{array}$ & l & / & l & I & l & 3.33 \\
\hline Jia et al. (2020) & $3.23_{-0.042}^{+0.035}$ & $3.27_{-0.025}^{+0.022}$ & $3.35_{-0.079}^{+0.053}$ & $2.02_{-0.16}^{+0.16}$ & $2.54_{-0.50}^{+0.41}$ & $2.07_{-0.027}^{+0.026}$ \\
\hline $\begin{array}{l}\text { CURRENT } \\
\text { STUDY }\end{array}$ & l & l & / & I & / & $1.53_{-0.027}^{+0.027}$ \\
\hline \multicolumn{7}{|c|}{ Compare with Wu et al. (2018) } \\
\hline & \multicolumn{6}{|c|}{ Subunits } \\
\hline & Subunit 10 & Subunit 11 & Subunit 18 & Subunit 19 & Subunit 26 & Subunit 27 \\
\hline Wu et al. (2018) & $1.53_{-0.069}^{+0.069}$ & $1.23_{-0.036}^{+0.036}$ & $1.28_{-0.051}^{+0.051}$ & $1.67_{-0.072}^{+0.072}$ & $2.02_{-0.078}^{+0.078}$ & $1.94_{-0.072}^{+0.072}$ \\
\hline $\begin{array}{l}\text { CURRENT } \\
\text { STUDY }\end{array}$ & $1.49_{-0.11}^{+0.11}$ & $1.13_{-0.12}^{+0.12}$ & $1.47_{-0.14}^{+0.14}$ & $1.79_{-0.12}^{+0.12}$ & $2.13_{-0.12}^{+0.12}$ & $2.07_{-0.11}^{+0.11}$ \\
\hline
\end{tabular}



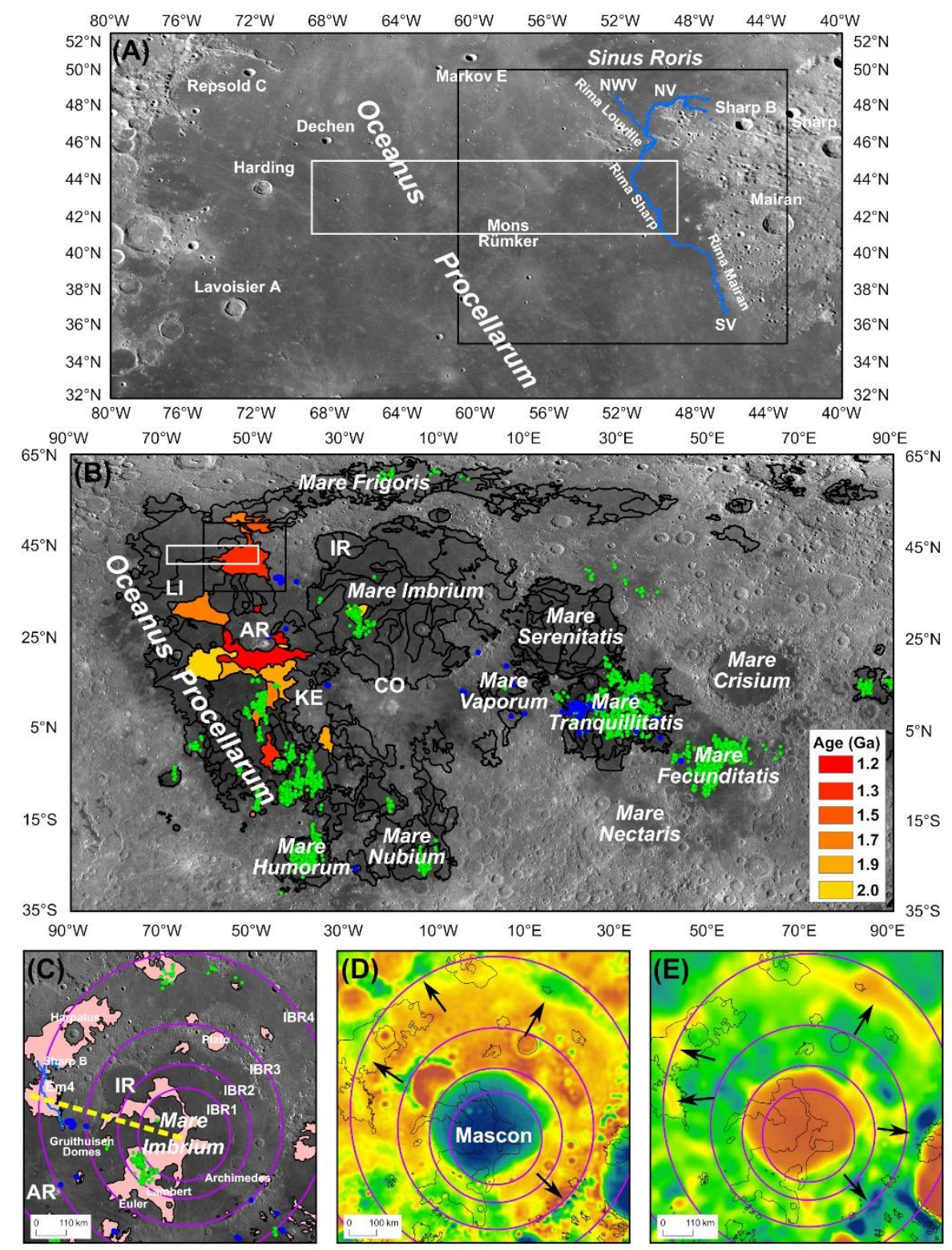

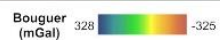

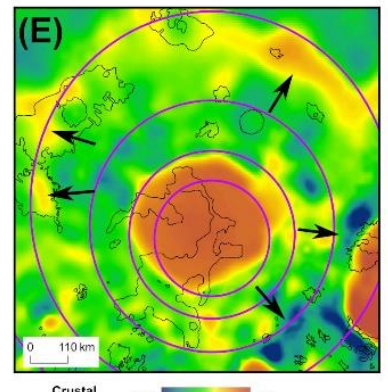

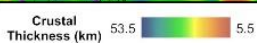

692 Figure 1. (A) Locations of the CE-5 landing region (white box) and the study area (black

693 box) in northern Oceanus Procellarum. Blue lines denote the sinuous rilles. SV, NV, and

694 NWV represent the south, north, and northwest source vents of Rima Mairan, Sharp, and

695 Louville, respectively. (B) Locations of potential young volcanic activity on the Moon. Black

696 lines denote mare boundaries (Hiesinger et al., 2011). Blue and green dots denote irregular

697 mare patches (Braden et al., 2014) and ring-moat dome structures (F. Zhang et al., 2020),

698 respectively. AR, Aristarchus plateau; IR, Sinus Iridum; CO, Copernicus crater; KE, Kepler

699 crater; LI, Lichtenberg crater. (C) Context of Em4 in the greater Imbrium basin region. Pink

700 patches indicate Eratosthenian-aged mare basalts. The yellow dashed line is the elevation

701 profile line in Fig. 8. IBR1, IBR2, IBR3, and IBR4 represent the $1^{\text {st }}, 2^{\text {nd }}, 3^{\text {rd }}, 4^{\text {th }}$ ring of the

702 Imbrium basin. (D) Bouguer anomalies and (E) crustal thickness of the Imbrium basin.

703 Purple circles indicate Imbrium basin rings (Spudis et al., 1988). Black arrows point to

704 potential gravity features of the Imbrium basin. 

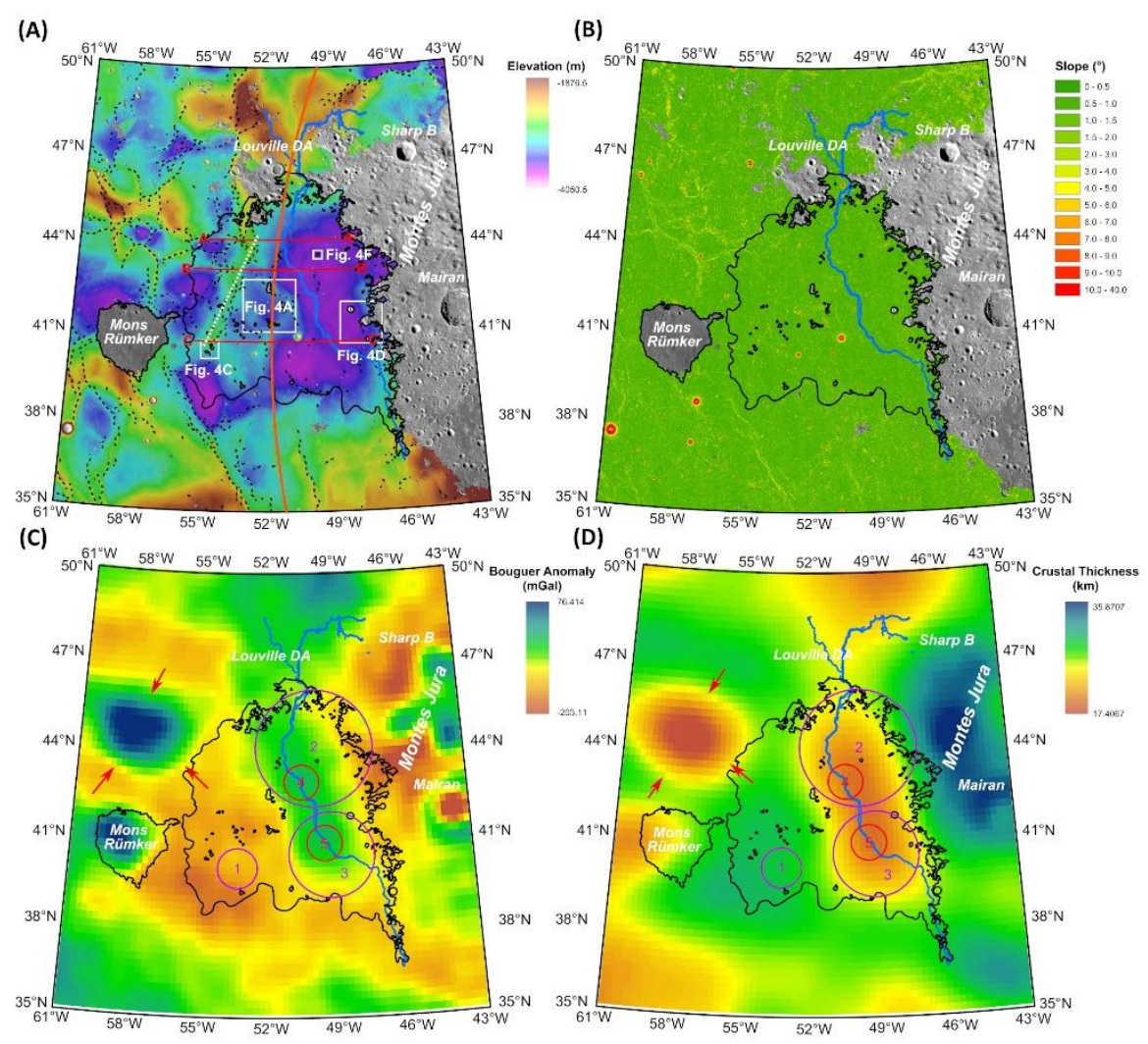

708 Figure 2. (A) Em4 is a flat mare plain west of Montes Jura. The orange line shows the 709 location of the outer Imbrium basin ring (Spudis et al., 1988). The black and white dashed

710 lines indicate wrinkle ridges and a large wrinkle ridge system, respectively. Red lines mark 711 the locations of the cross-section profiles in Fig. 3. White boxes indicate locations of features 712 shown in Fig. 4. The basemap is a SLDEM2015 overlaid on Kaguya TC Morning Map. (B) 713 Slope map of Em4, calculated from SLDEM2015, with a baseline length of $\sim 180 \mathrm{~m}$. (C) The 714 Bouguer anomaly and (D) crustal thickness of Em4 (Wieczorek et al., 2013). Purple and red 715 circles indicate QCMAs mapped by Evans et al. (2016) and Chisenga et al. (2020),

716 respectively. The red arrows denote an impact crater filled with thick basaltic materials 717 (Chisenga et al., 2020). The results of Evans et al. (2016) (QCMAs 1,2, and 3) and Chisenga 718 et al. (2020) (QCMAs 4 and 5) display differences but it is clear there are at least two 719 QCMAs in the eastern part of the Em4 unit. 

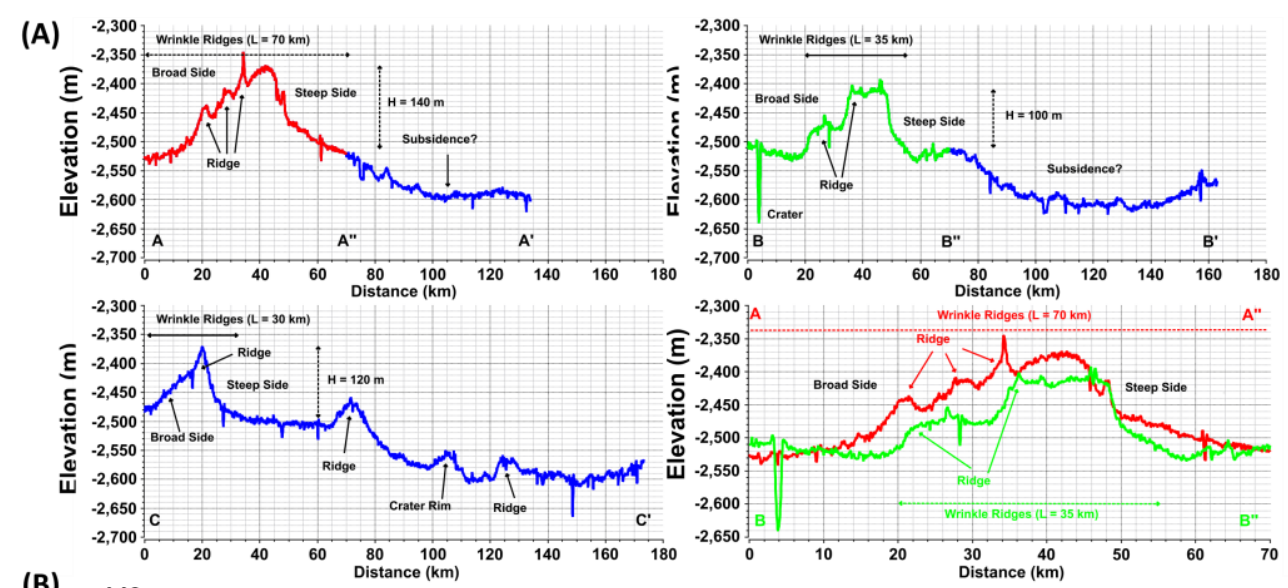

(B)

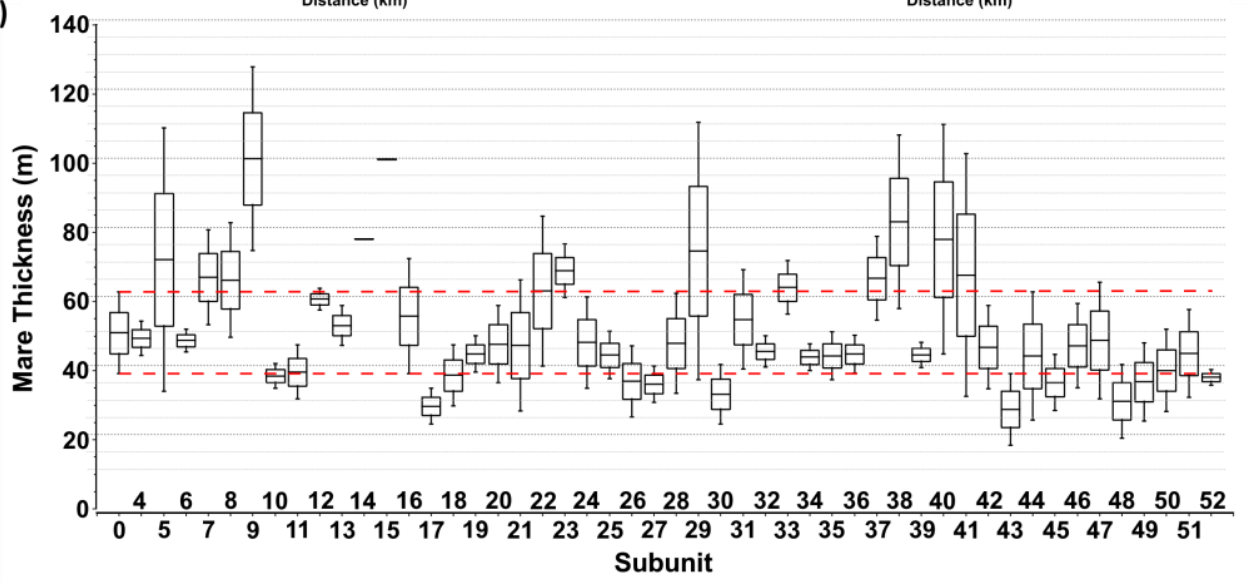

Figure 3. Cross-section profiles (AA', BB', and CC') across Em4. The elevations of Em4 decrease from west to east and the wrinkle ridges exhibit elevations up to $\sim 200 \mathrm{~m}$. Profile locations are shown in Fig. 2A. (B) Mare basalt thickness measured for each $1^{\circ} \times 1^{\circ}$ subunit (except for Subunits 1, 2, and 3 due to heavy contamination by adjacent highlands). "Subunit 0 " at the left represents the mean thickness of all the 49 subunits. Subunits 14 and 15 do not have any penetrating craters, therefore their upper limit thickness cannot be constrained. Mare thickness is constrained by crater excavation technique (Note S1): the excavation depth of the smallest penetrating crater of each subunit is regarded as the lower limit on thickness (lower short line); and the excavation depth of the largest nonpenetrating crater of each subunit is regarded as the upper limit on thickness (upper short line); and the average of upper limit and lower limit is regarded as the mean value (middle short line). 

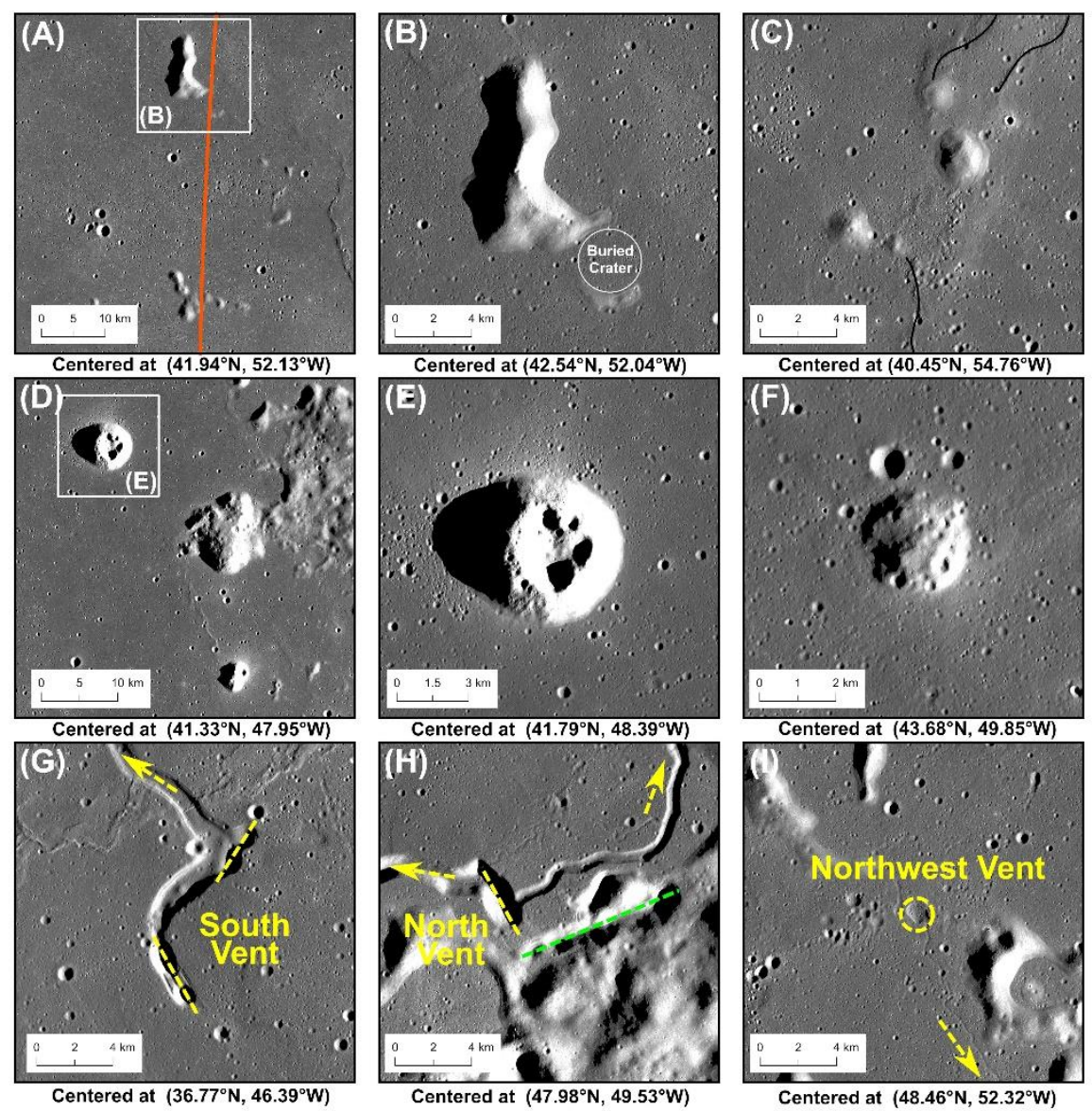

Figure 4. (A, B, \& C) Kipukas in Em4 as shown on the Kaguya TC Morning map. Some of the kipukas lie along the Imbrium basin outer ring (orange line) (Spudis et al., 1988). (D, E, \& F) Mairan silica-rich domes (Glotch et al., 2011), including Mairan NW, T, Middle, and South Domes. (G, H, \& I) South, north, and northwest source vents of the sinuous rille system. Yellow arrows show the lava flow direction. The south vent consists of two linear vents (yellow dashed lines, $\sim 4 \mathrm{~km}$ and $\sim 3 \mathrm{~km}$ long, respectively). The green dashed line indicates a vent adjacent to the north vent, which may be on the top of a dike. A small sinuous rille also originated from the north vent. The yellow dashed circle indicates the source depression of the northwest vent. 

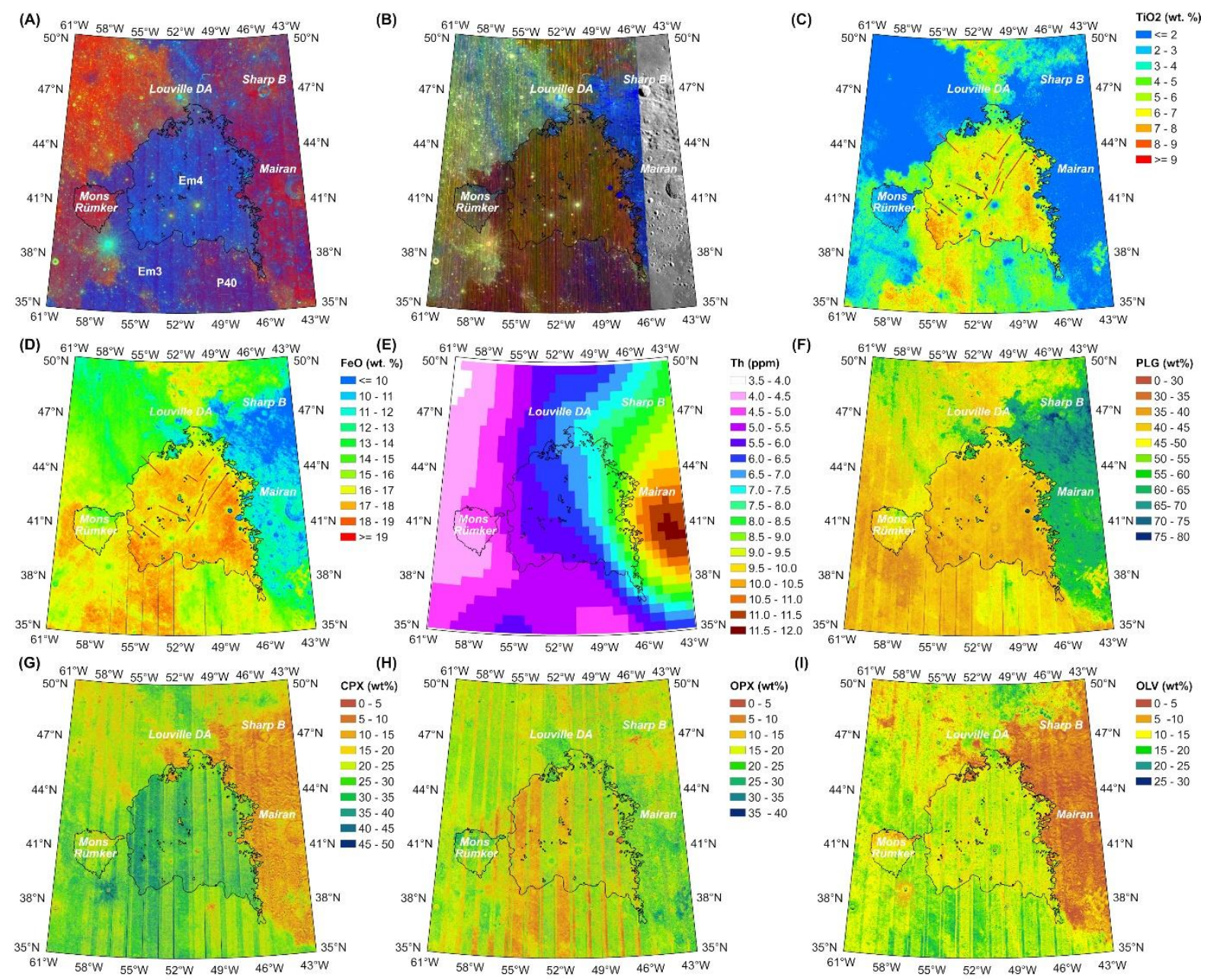

Figure 5. (A) False color ratio map of Em4 based on Kaguya MI data. Red: 750 nm/415 nm, Green: $750 \mathrm{~nm} / 950 \mathrm{~nm}$, Blue: $415 \mathrm{~nm} / 750 \mathrm{~nm}$. (B) IBD color composite map of Em4 based on $\mathrm{M}^{3}$ data. Red: IBD1000, Green: IBD2000, Blue: Reflectance at $1580 \mathrm{~nm}$. (C) $\mathrm{TiO}_{2}$ abundance map of Em4 (Sato et al., 2017). (D) FeO abundance map of Em4 (Lemelin et al., 2015). Red lines indicate ejecta materials/rays. (E) Th contents of Em4. (F) PLG, (G) CPX, (H) OPX, and (I) OLV abundances of Em4 produced by Lemelin et al. (2015) using Kaguya MI data. 
(A)
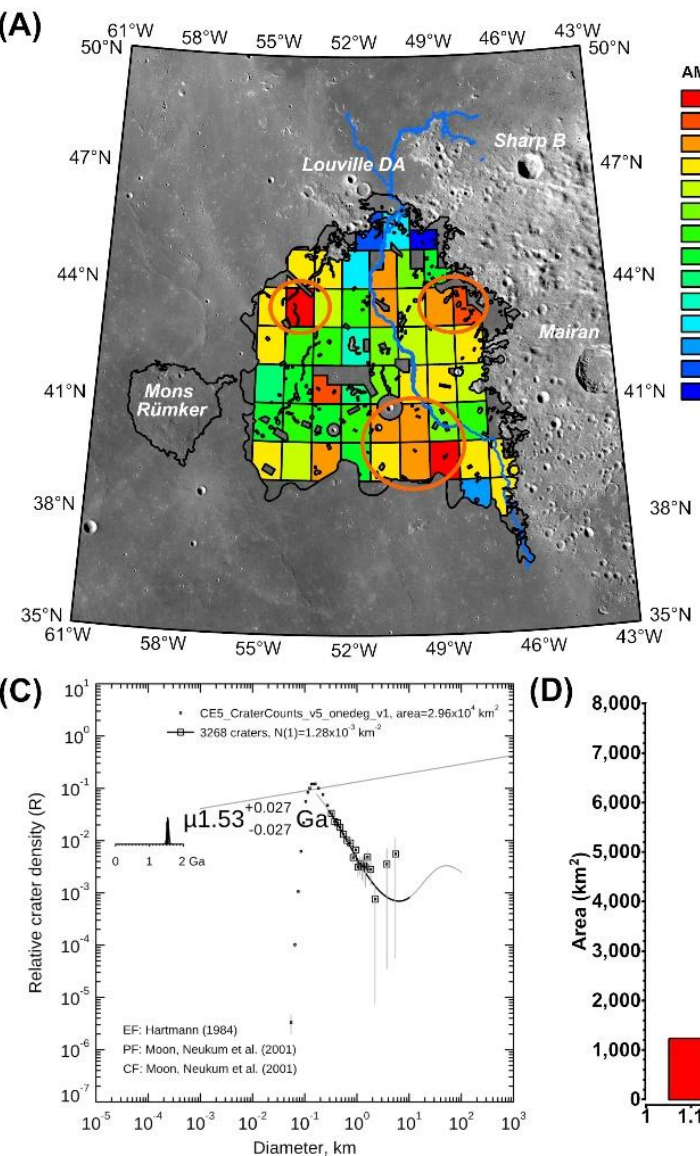

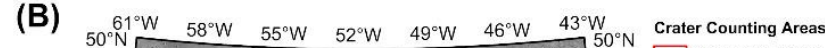

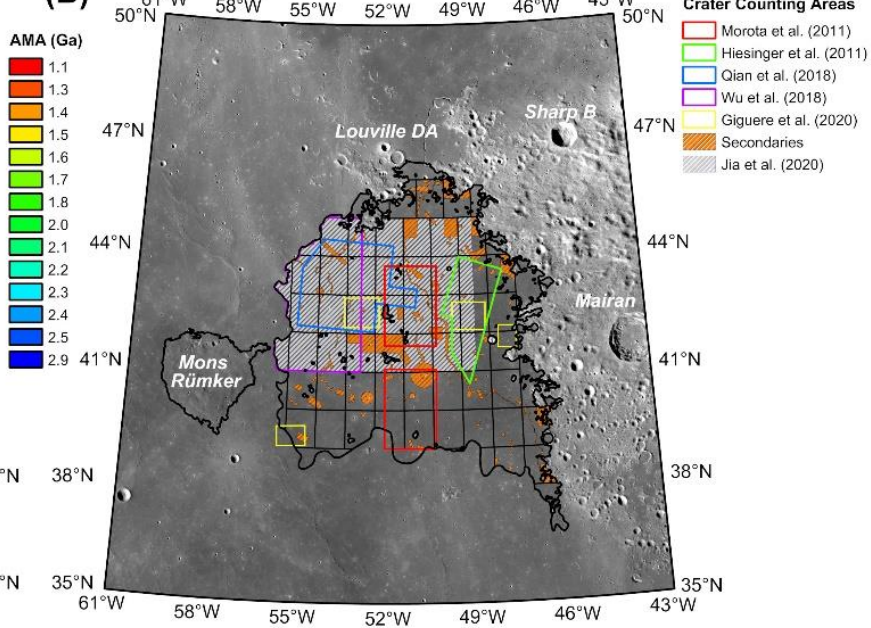

(D)

Figure 6. (A) Absolute model ages of 52 subunits in Em4. Orange circles indicate locations of potential youngest mare areas discussed in Section 3.3. (B) Crater counting areas from different studies listed in Tab. 2. Orange dashed polygons represent areas with abundant secondary craters that have been excluded from our CSFD measurements. (C) Mean AMA of Em4, shown as R plot, combining crater counting results of all subunits. (D) Histogram of crater counting results, with a mean value of $1.68 \mathrm{Ga}$ and a median of $1.6 \mathrm{Ga}$. All values are calculated based on the occupied area of each subunit. 

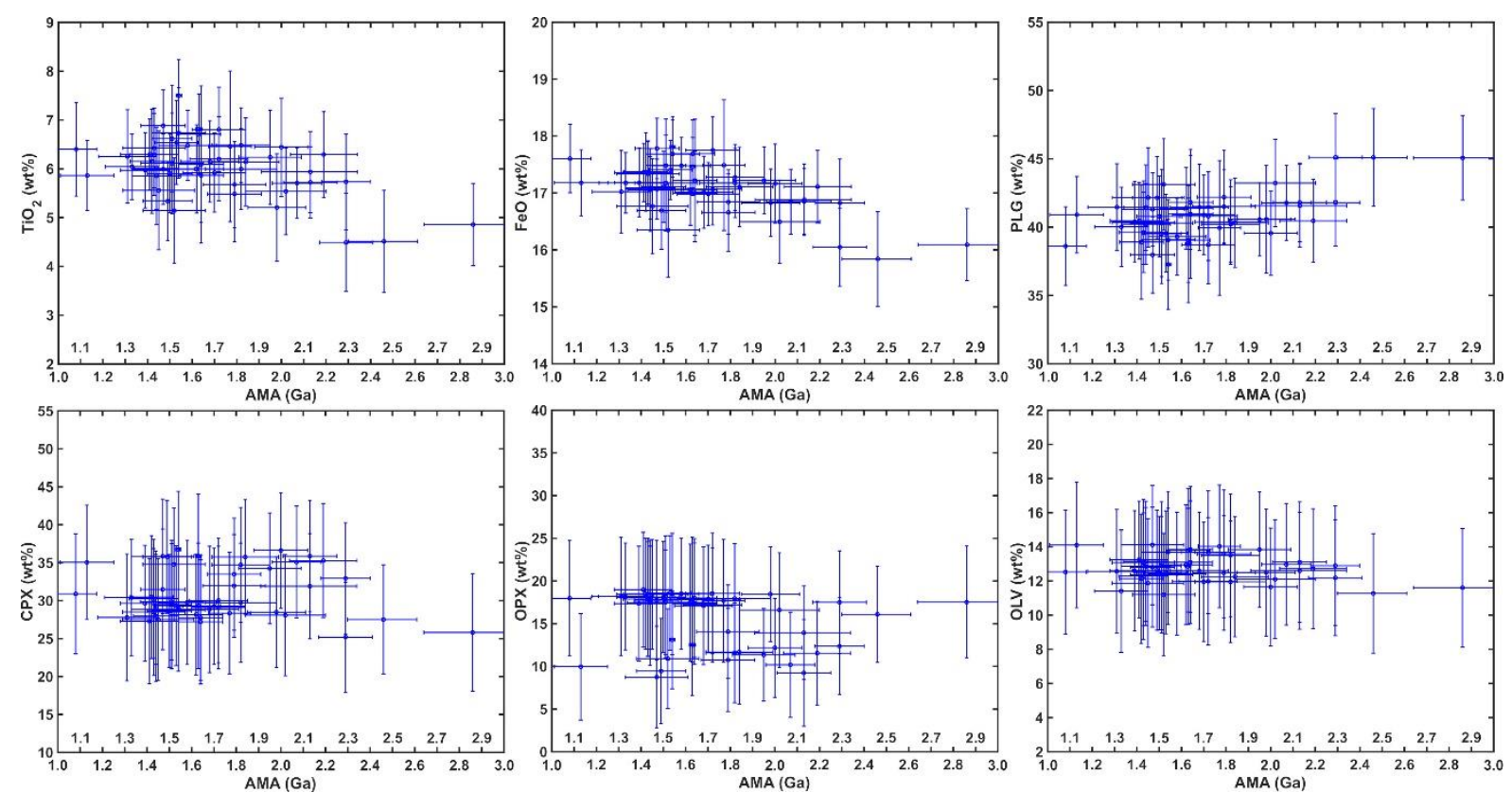

Figure 7. The relationship between AMAs of each subunit in $\mathrm{Em} 4$ and their $\mathrm{TiO}_{2}$ and $\mathrm{FeO}$ abundances, PLG, CPX, OPX, and OLV volume. The center points of the horizontal lines represent AMAs, while the error bars are from Poisson timing analyses. The center points of vertical lines represent the mean value of composition in each subunit, while the error bars represent one standard derivation. $\mathrm{The}^{\mathrm{TiO}_{2}}$ and $\mathrm{FeO}$ abundances of $\mathrm{Em} 4$ increases from 2.3 Ga to $1.5 \mathrm{Ga}$ and decreases to $1.0 \mathrm{Ga}$. 

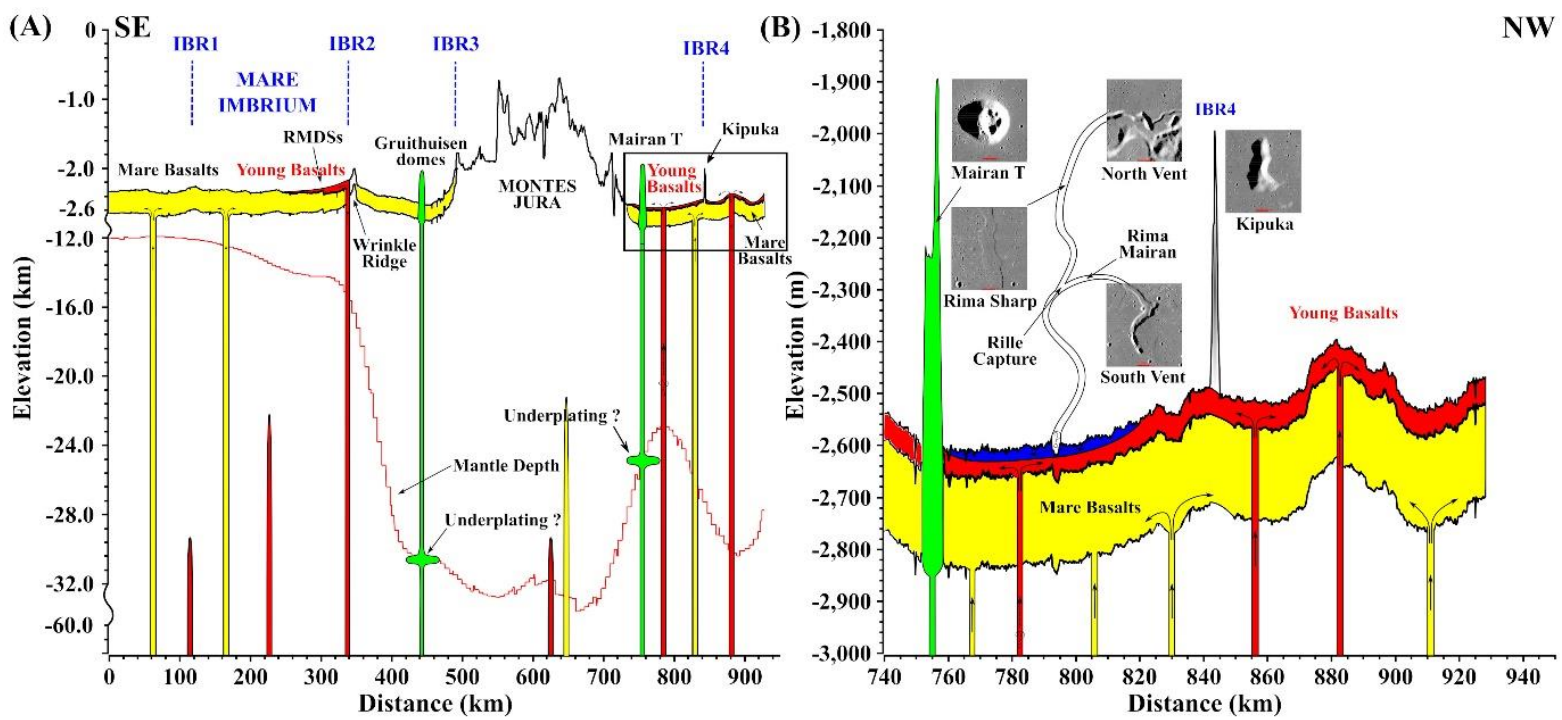

809 Figure 8. Generalized geologic cross-sections and topographic profiles of the CE-5 landing 810 region and vicinity. Yellow, red, and blue colors indicate Imbrian-aged, Eratosthenian-aged 811 mare basalts, and mare basalts from sinuous rilles. Green colors indicate silica-rich domes 812 (Wilson and Head, 2003). IBR represents the Imbrium basin rings. Elevations are taken from 813 SLDEM2015 data along the yellow dashed line in Fig. 1. Not all elements in this figure are 814 shown at the same scale. (A) Geological cross-section of the northwest Imbrium basin and 815 northern Oceanus Procellarum showing the setting of Em4. The red line indicates the crust816 mantle boundary (depth to mantle) (Wieczorek et al., 2013). RMDSs on the Eratosthenian817 aged mare basalts are from Zhang et al. (2020). (B) The stratigraphic relationships of the 818 major units and features in the vicinity of Em4. The location of the profile is shown as a 819 black box in Fig. 8A. Corresponding surface features are shown as images. 

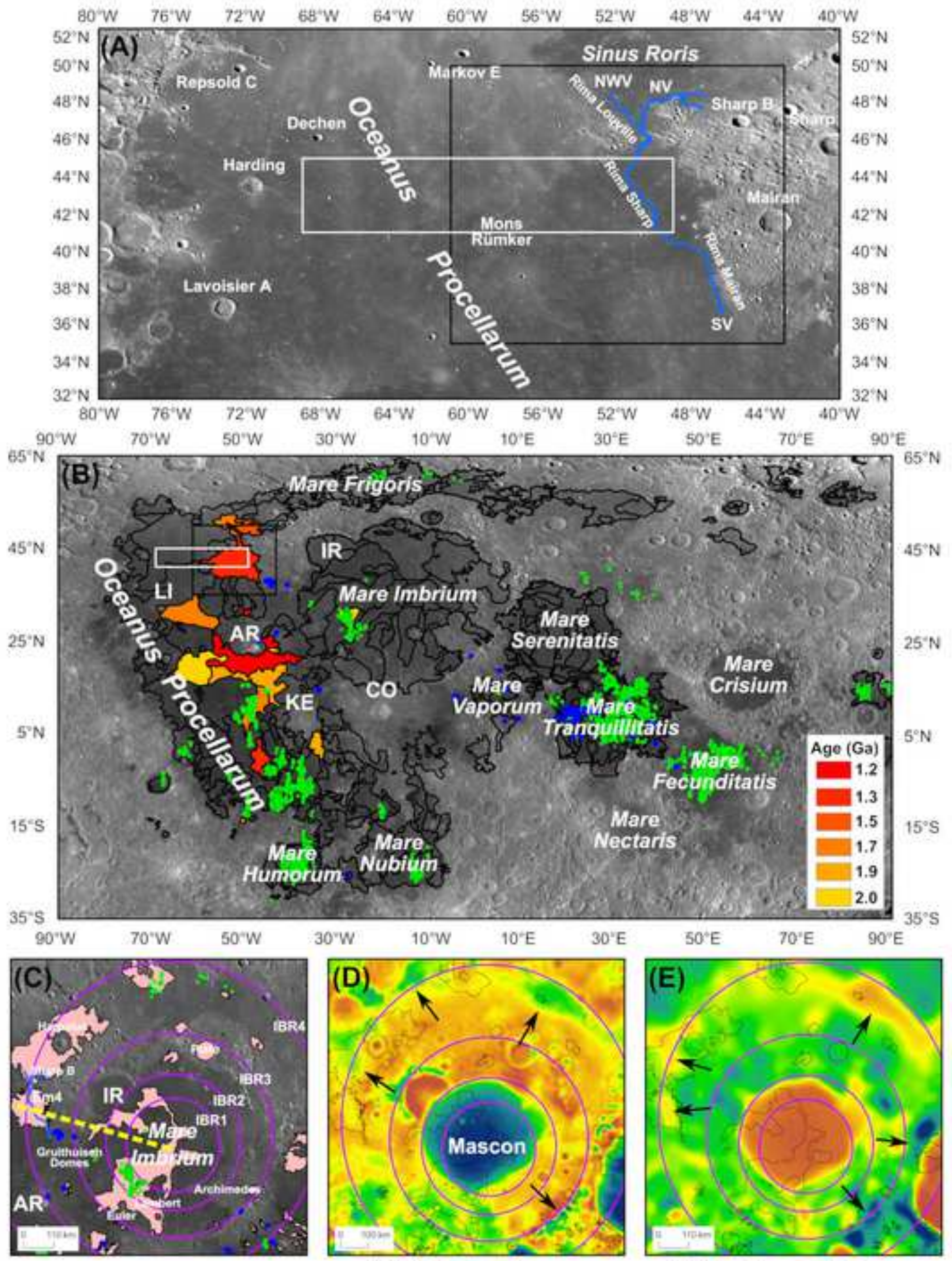

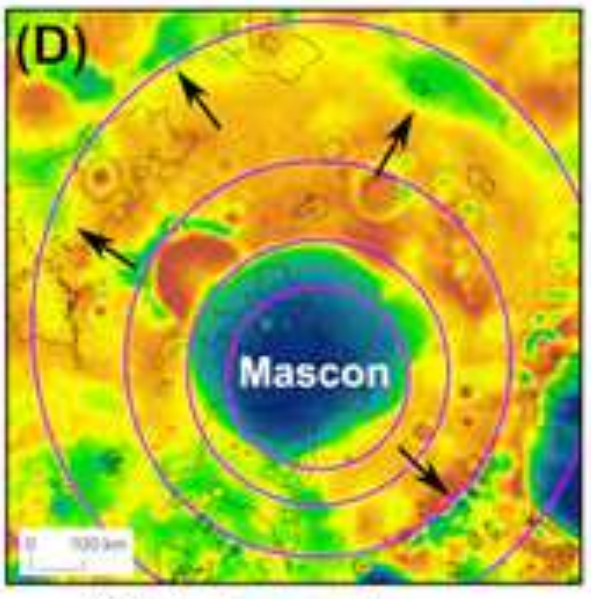

Dosogut an

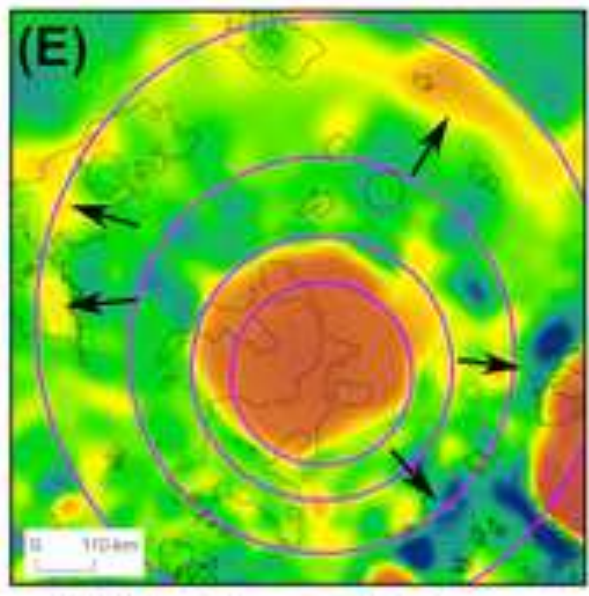

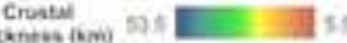


(A)

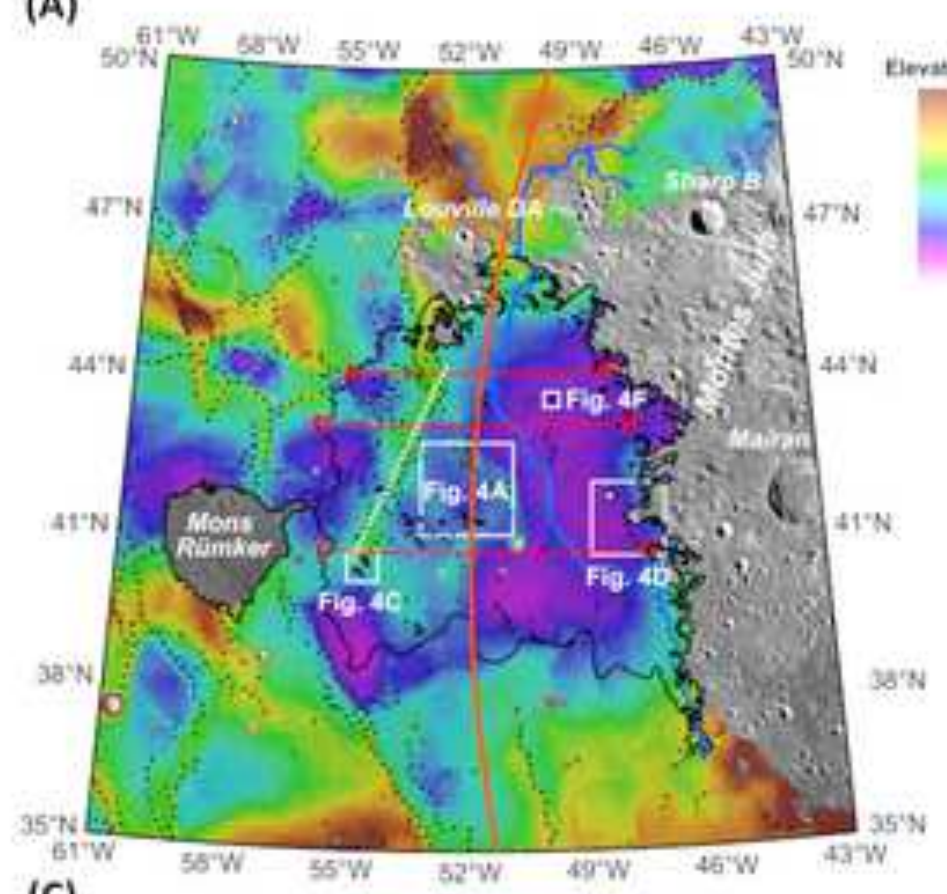

(B)

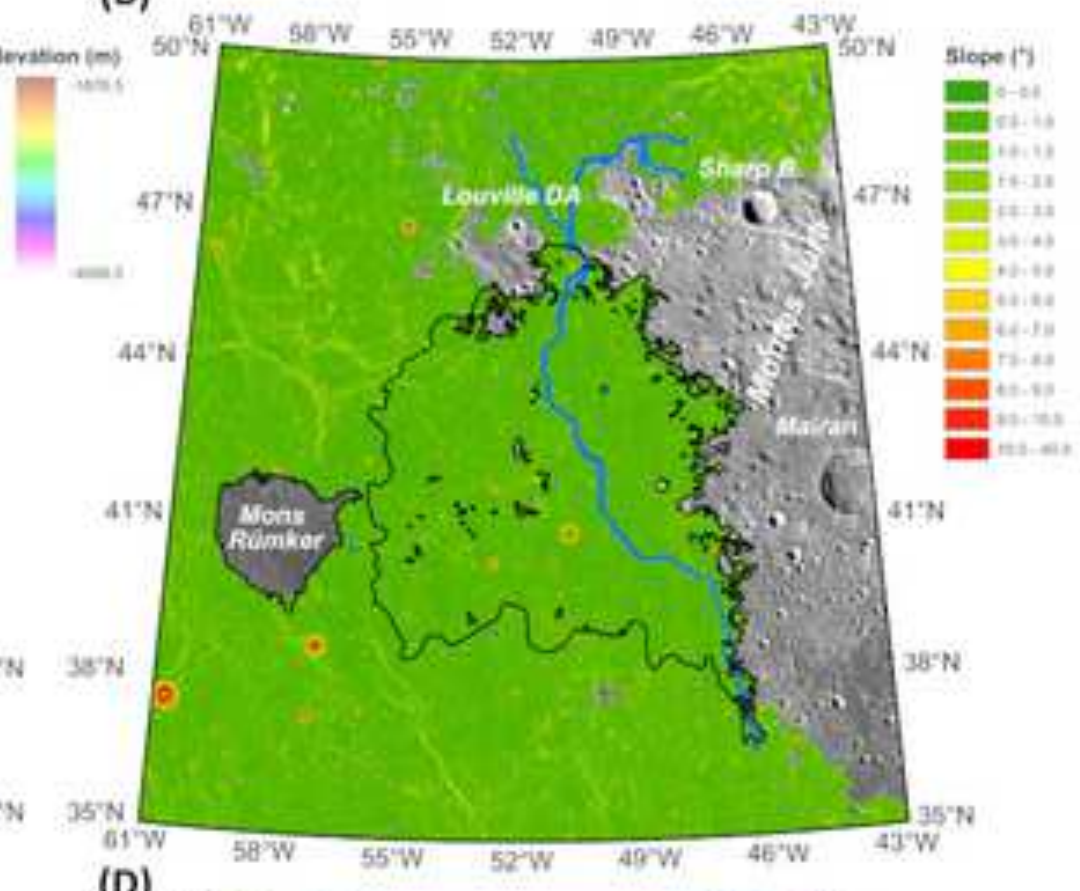

(C)
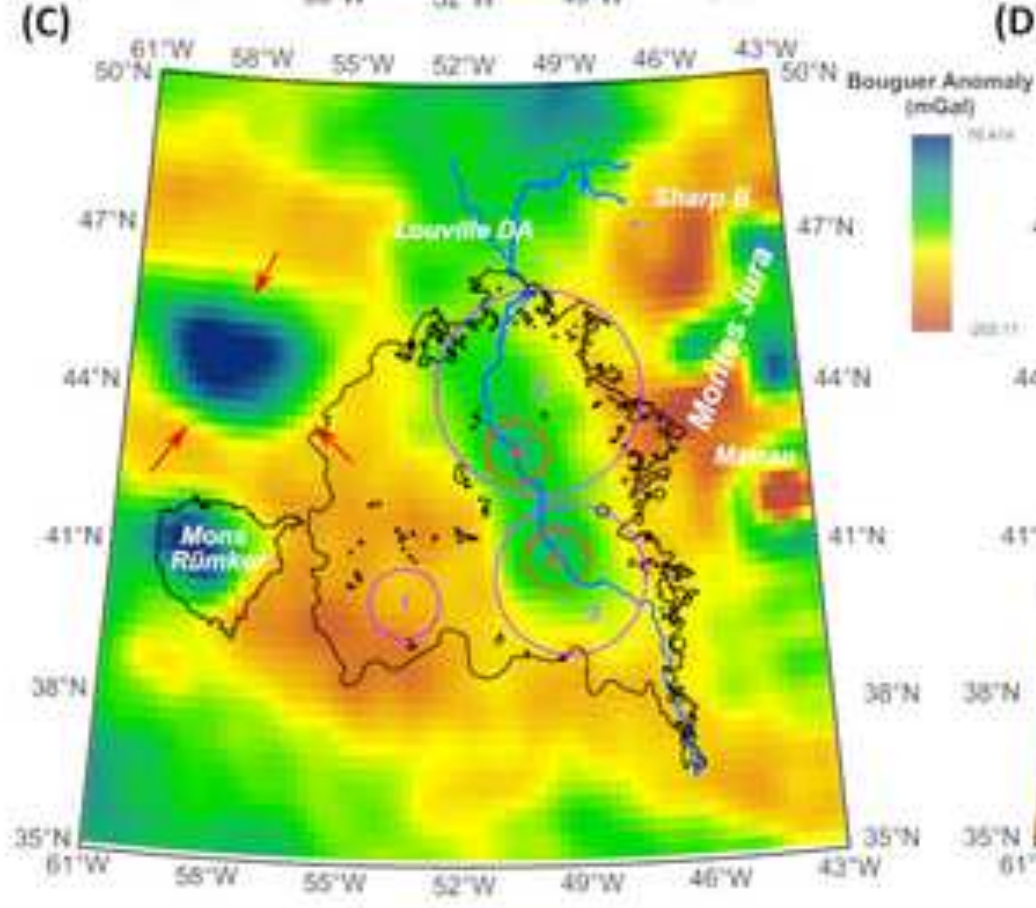

(D)

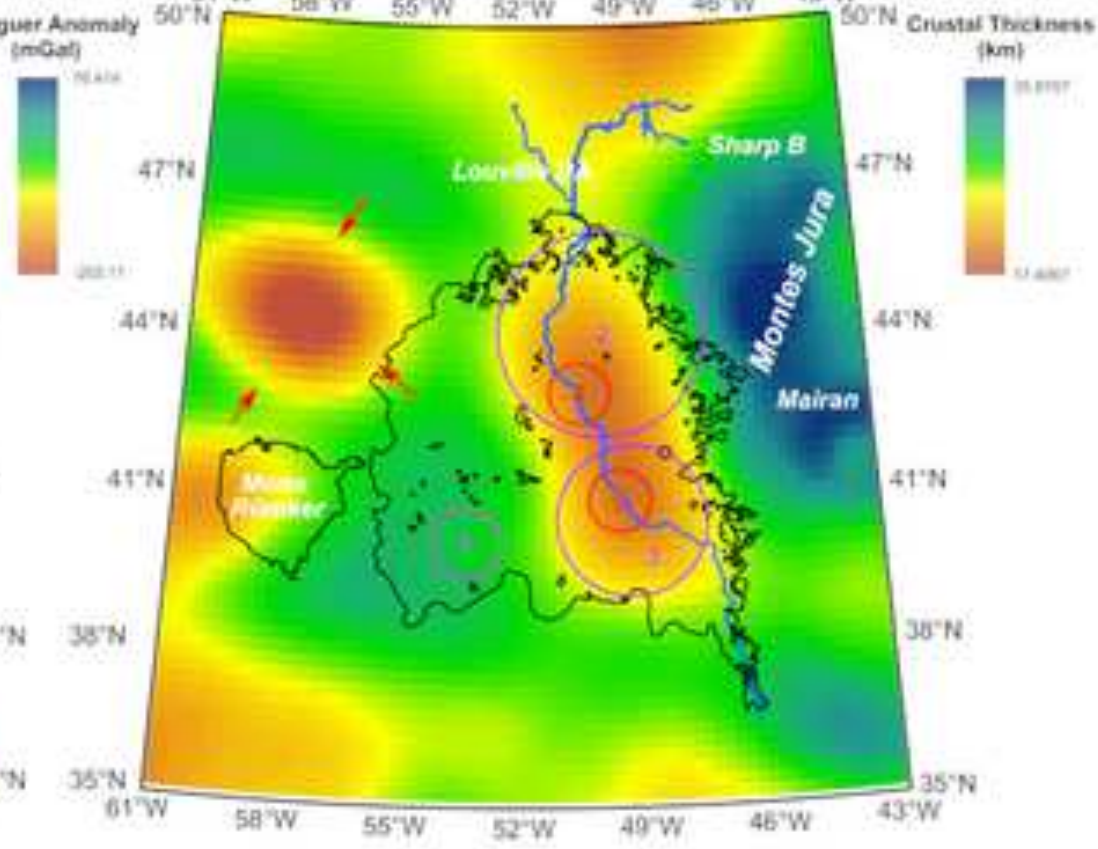




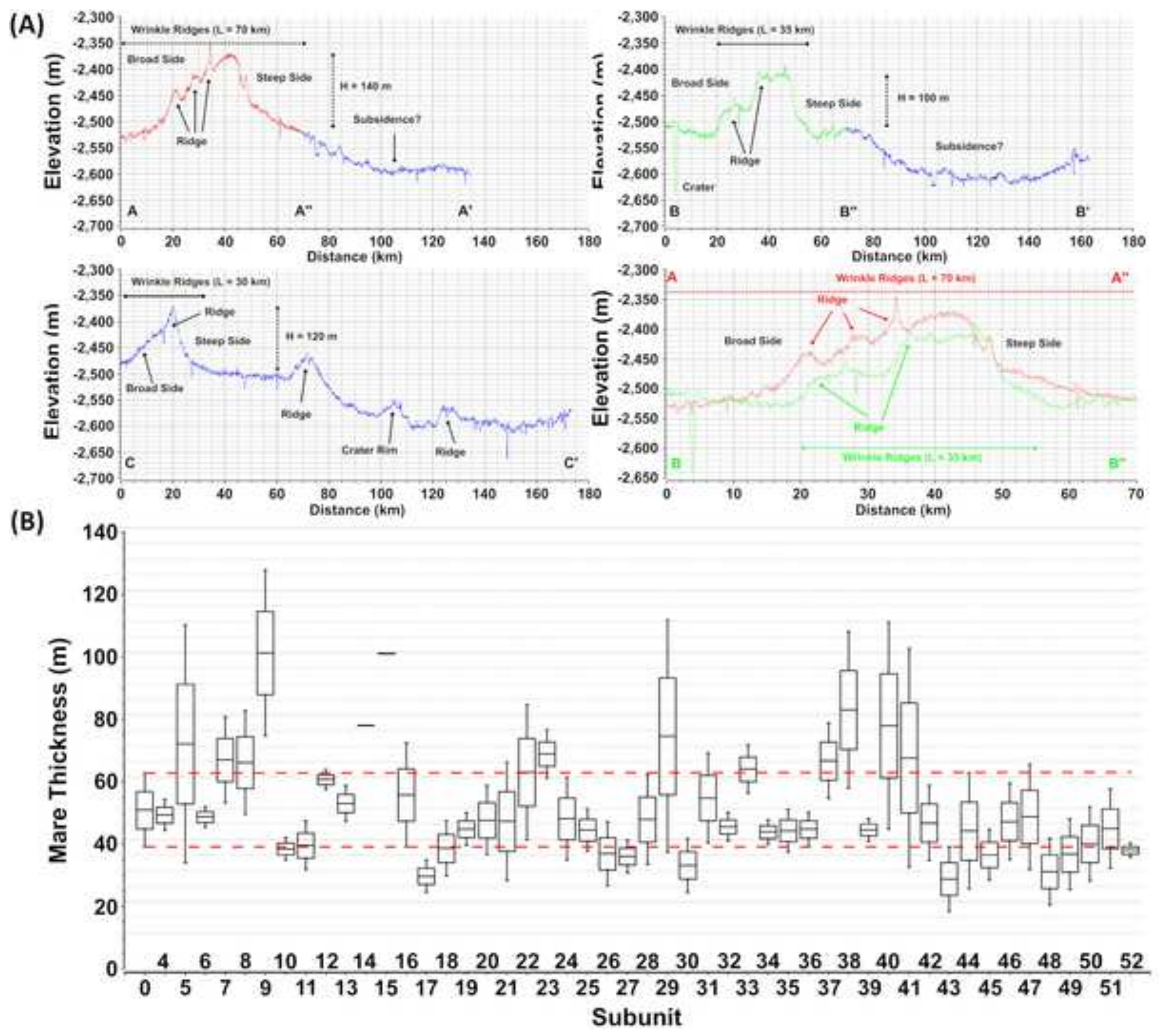




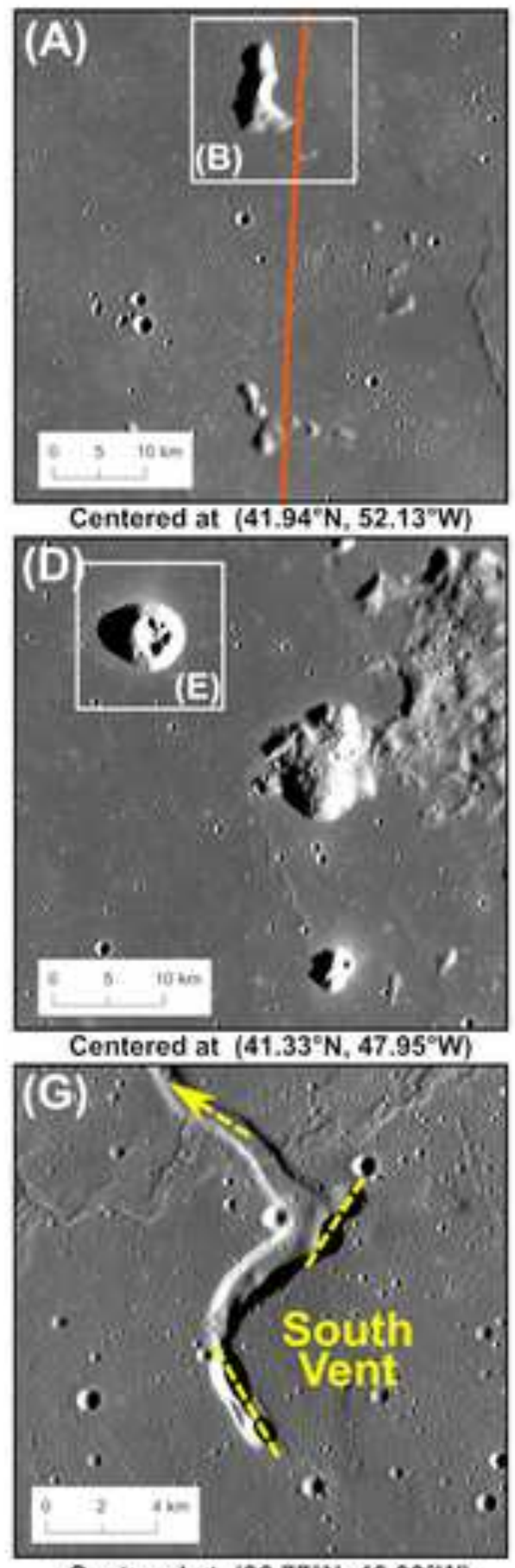

Centered at $\left(36.77^{\circ} \mathrm{N}, 46.39^{\circ} \mathrm{W}\right)$

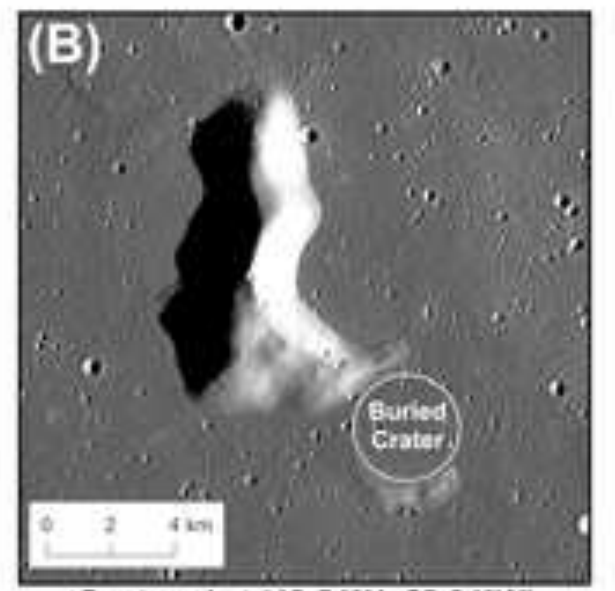

Centered at $\left(42.54^{\circ} \mathrm{N}, 52.04^{\circ} \mathrm{W}\right)$

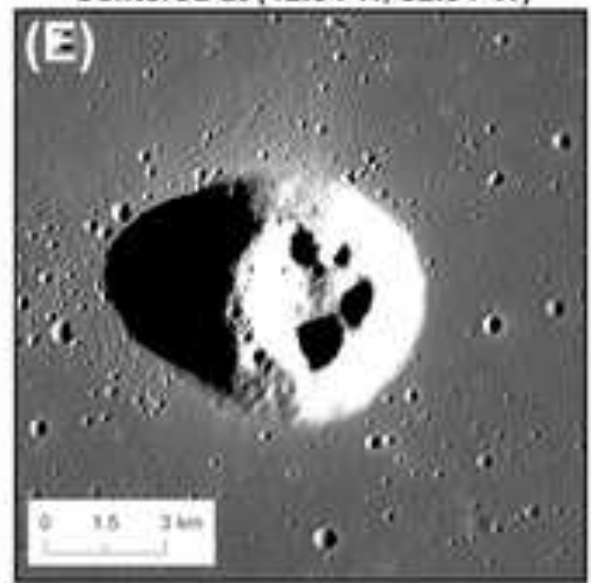

Centered at $\left(41.79^{\circ} \mathrm{N}, 48.39^{\circ} \mathrm{W}\right)$

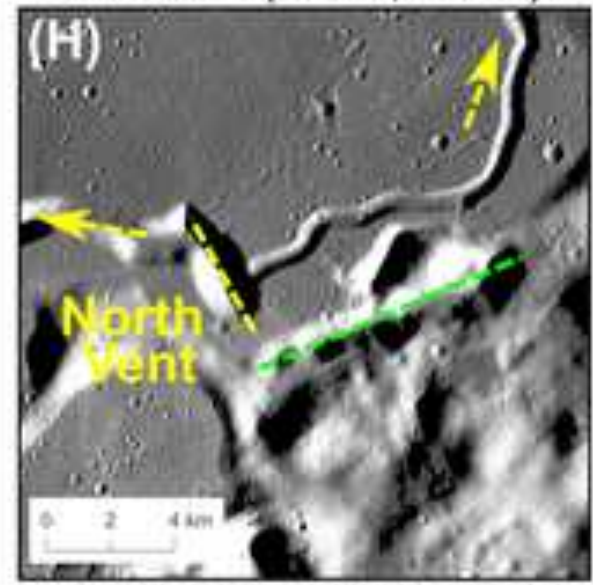

Centered at $\left(47.98^{7} \mathrm{~N}, 49.53^{\circ} \mathrm{W}\right)$

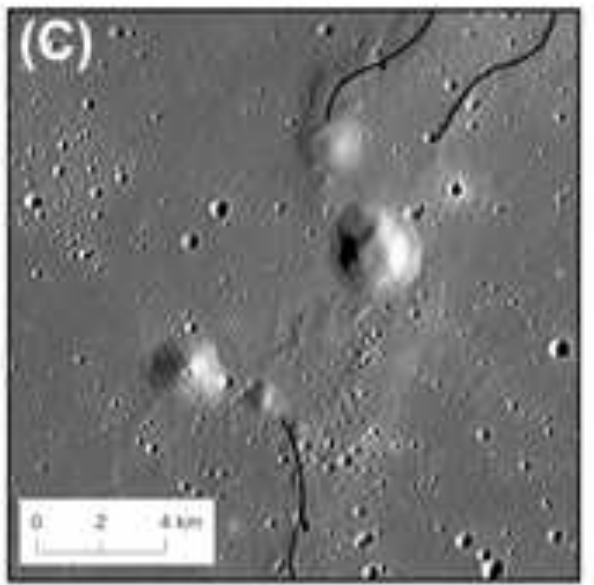

Centered at $\left(40.45^{\circ} \mathrm{N}, 54.76^{\circ} \mathrm{W}\right)$

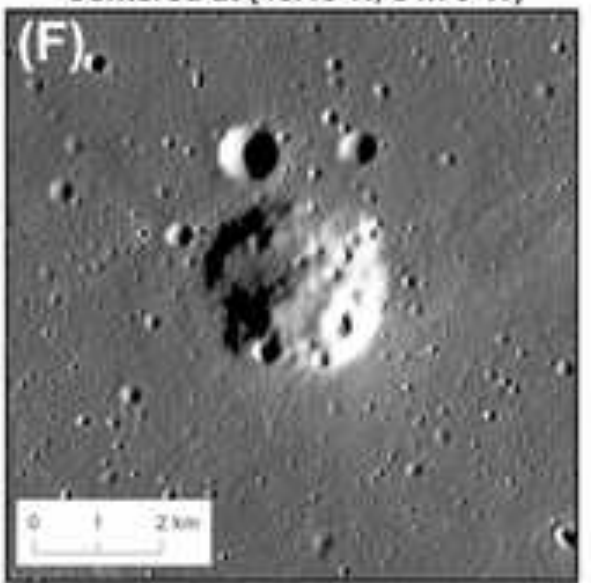

Centered at $\left(43.68^{\circ} \mathrm{N}, 49.85^{\circ} \mathrm{W}\right)$

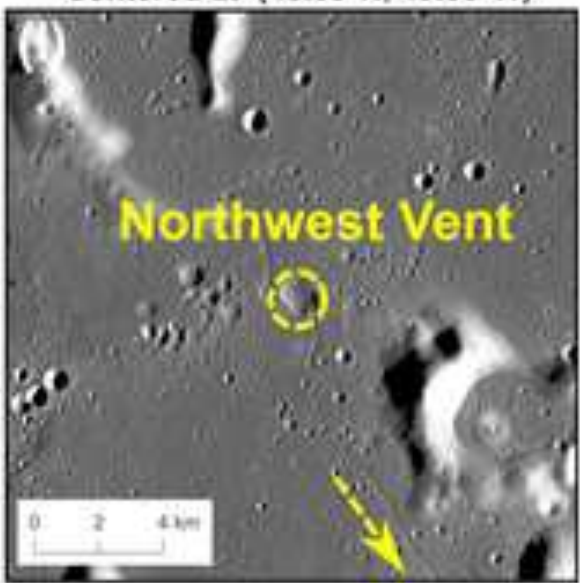

Centered at $\left(48.46^{\circ} \mathrm{N}, 52.32^{\circ} \mathrm{W}\right)$ 


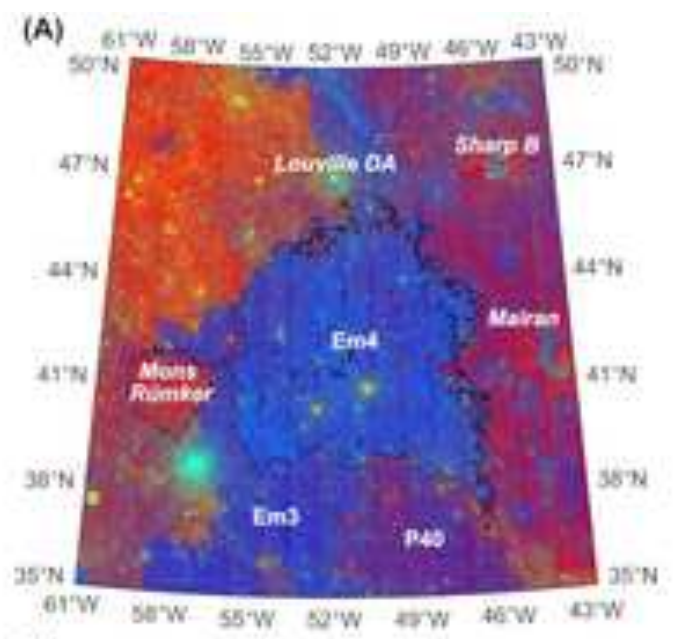

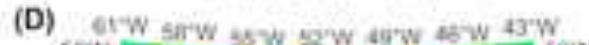

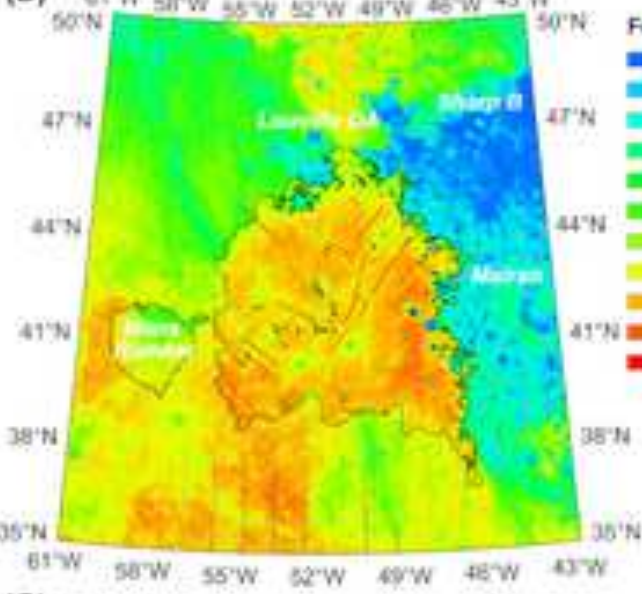

(G)

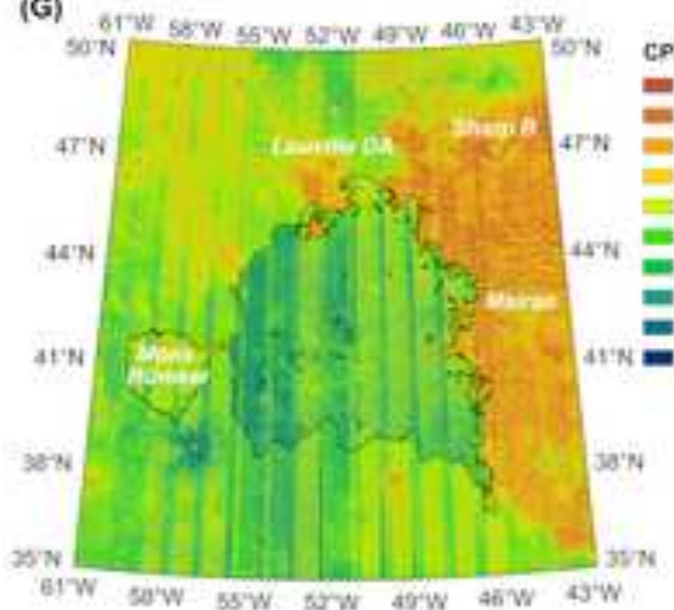

(B)

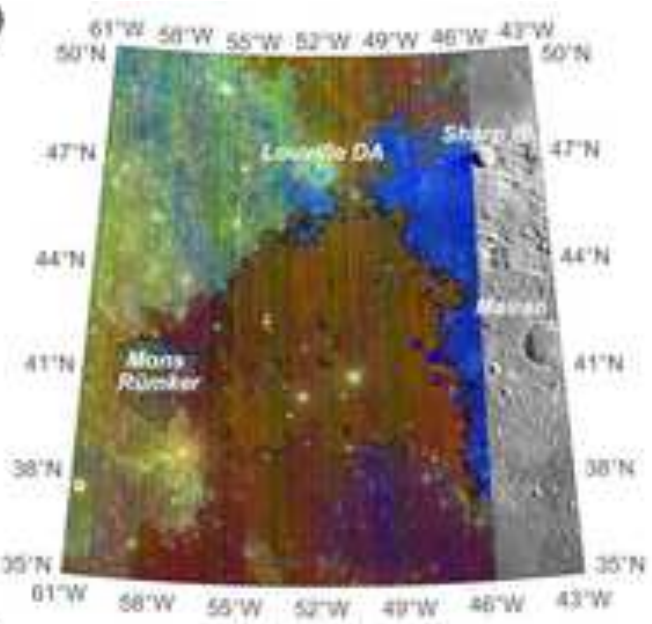

(E) Feo (int s)

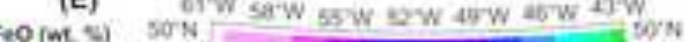
$=2 \times 10$ 10- 11 $=11-12$ $=12.13$ =13-19 =14-15 $=15-16$ =17-18 m

$39+1$

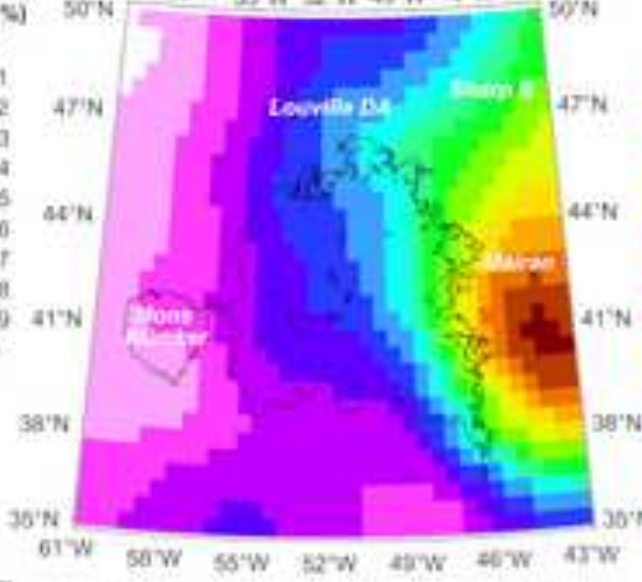

(H) coximtsy $=0-5$ $=5-10$ : $=10+15$
$15+20$ $-20.25$

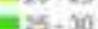
$=80.25$ = $=40.45$

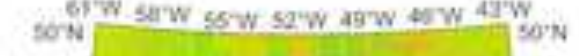

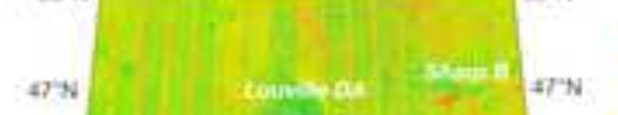
4

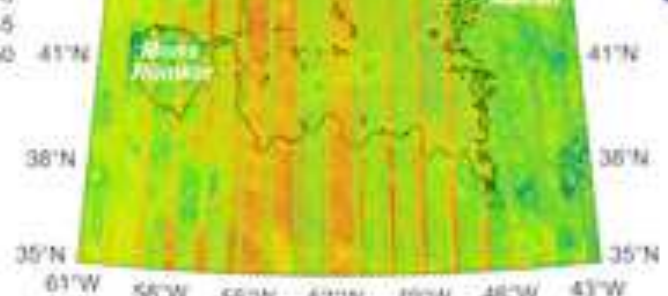

(C)

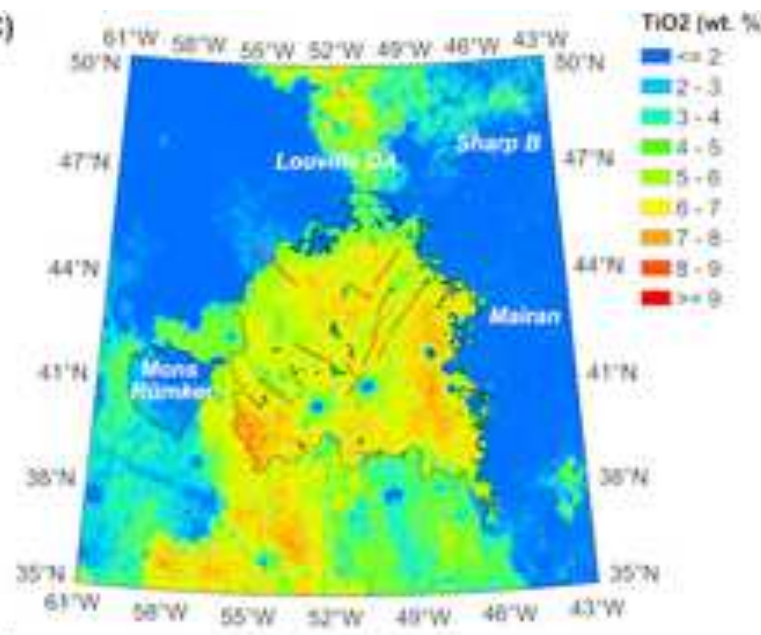

(F)

Th (ppm) 400.4

$=43-50$

$=50.55$

$=5.60$

$=60-65$

$=6.7 .70$

cho.7n

- $=89.55$

mas: 90 $000 \cdot 45$ =s 05.100 $\begin{array}{r}10.0-508 \\ =105-510 \\ \hline\end{array}$ $=110-11$.

an-120 opx (w) $\mathrm{OPX}$ (w)
$=\mathrm{D}-5$ $=0.5$ $=5-10$ $=10+13$
$=15.20$ $=20.25$

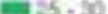
$=30.35$ $=35.40$

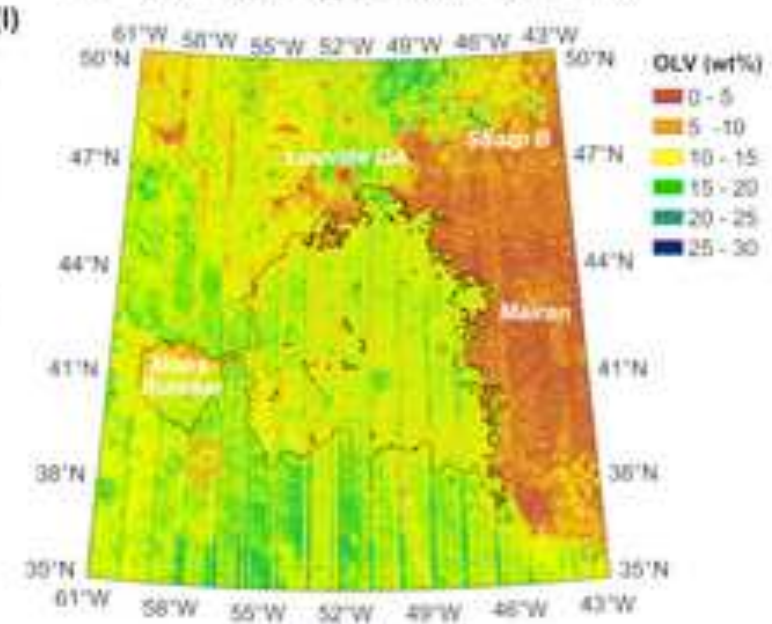


(A)

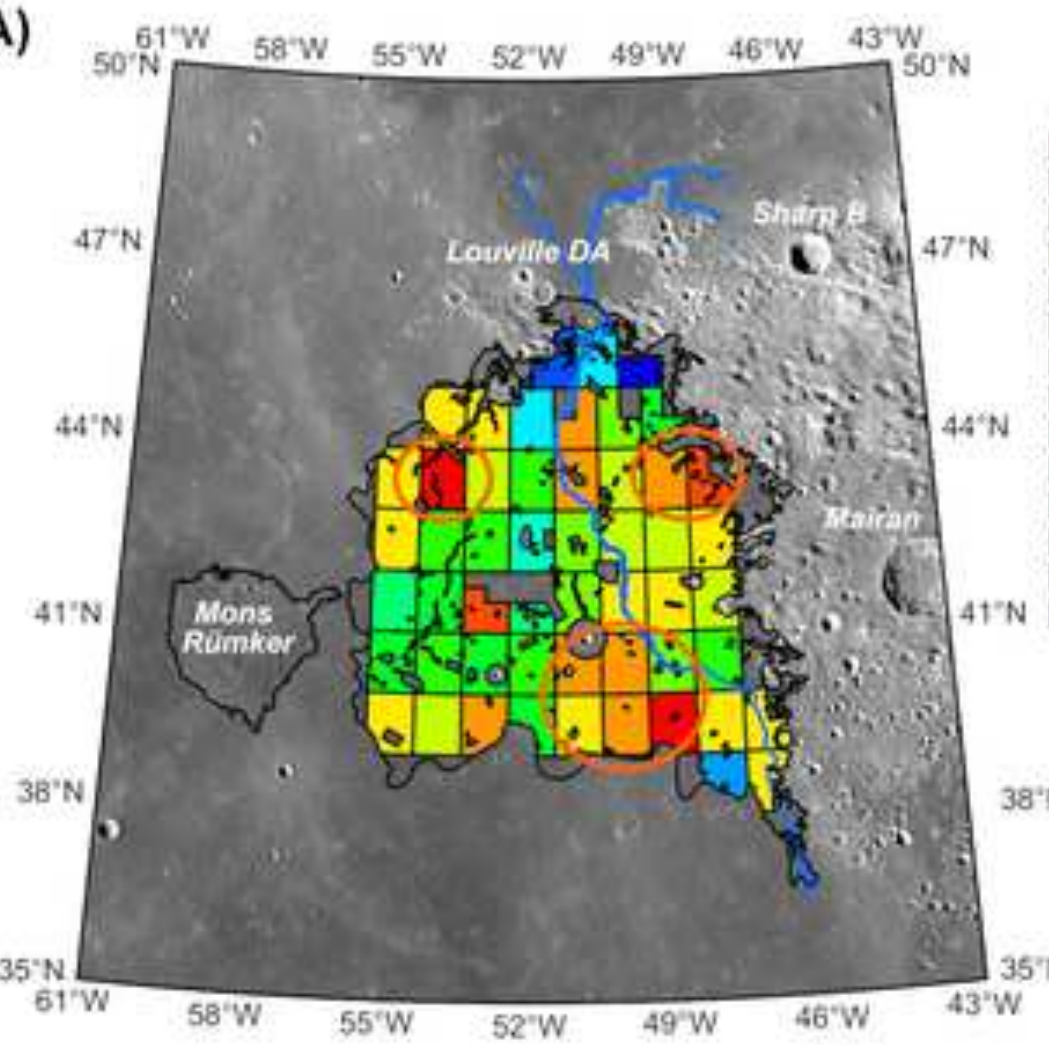

(B)

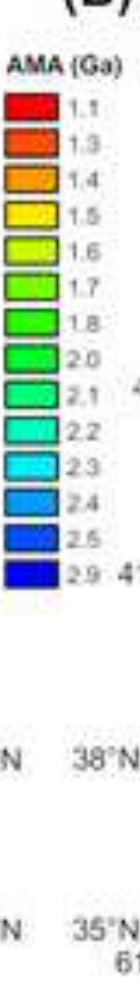

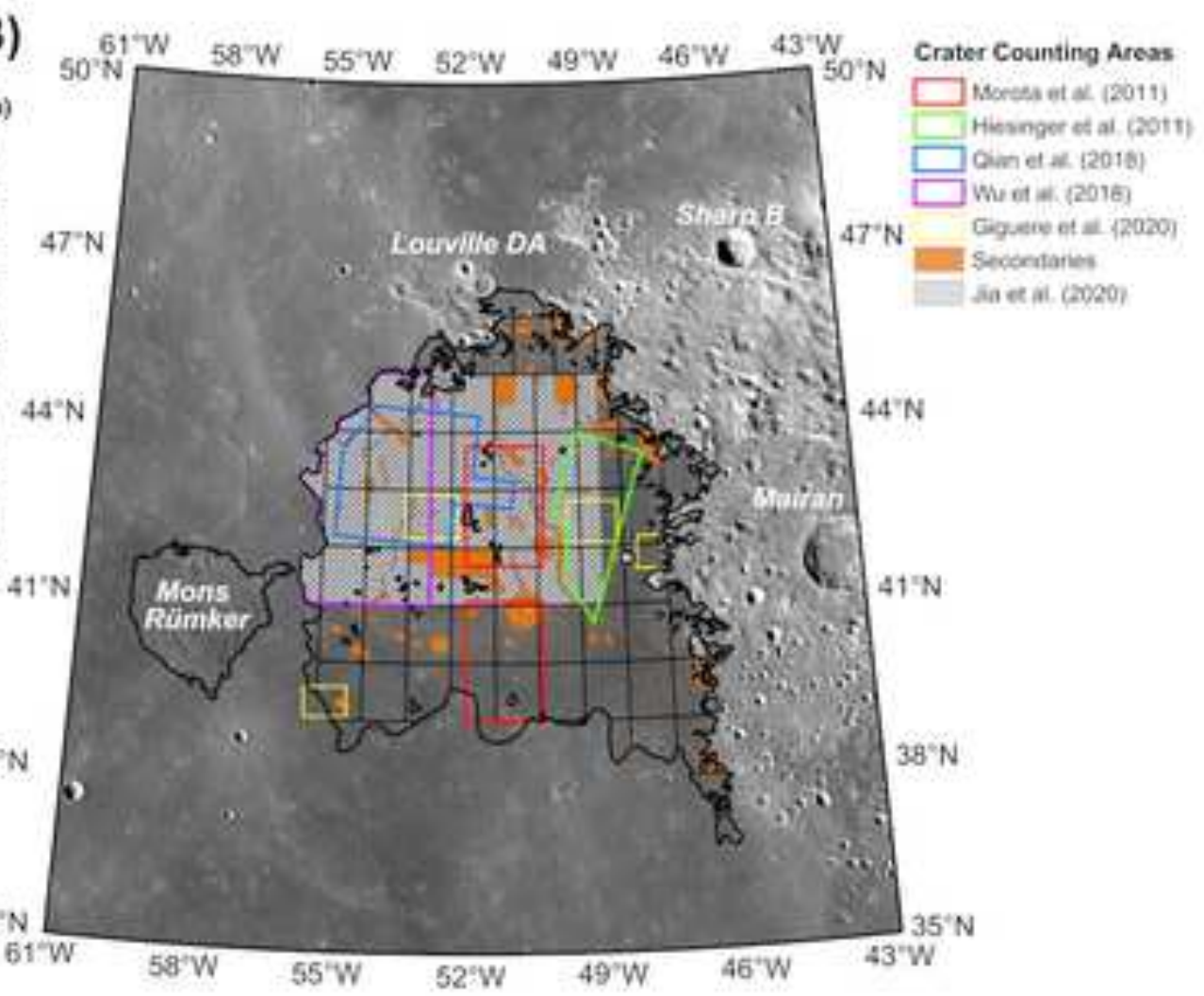

(C)

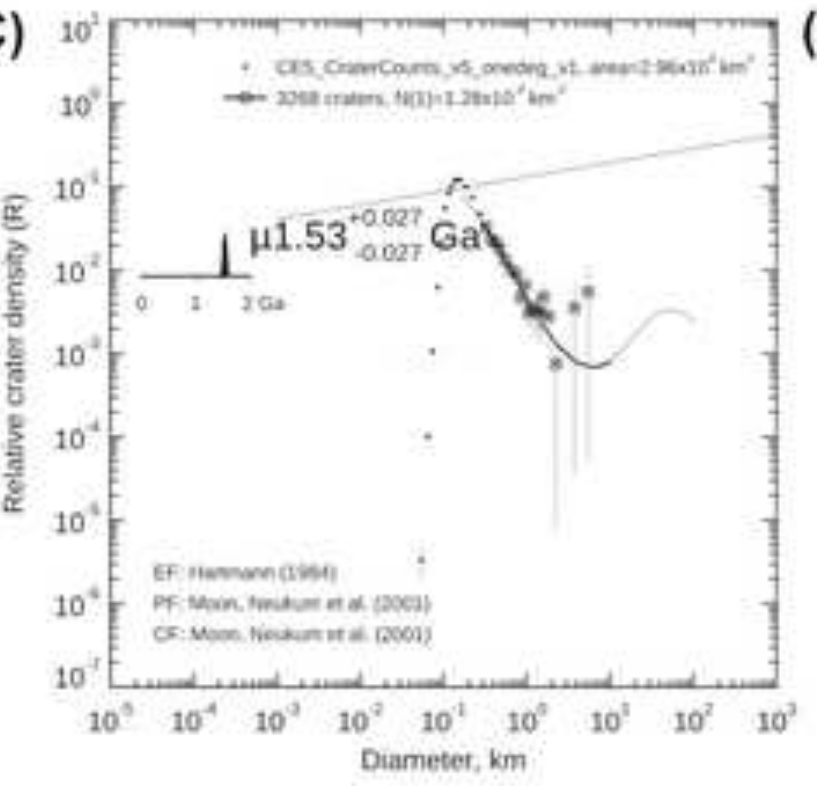

(D)

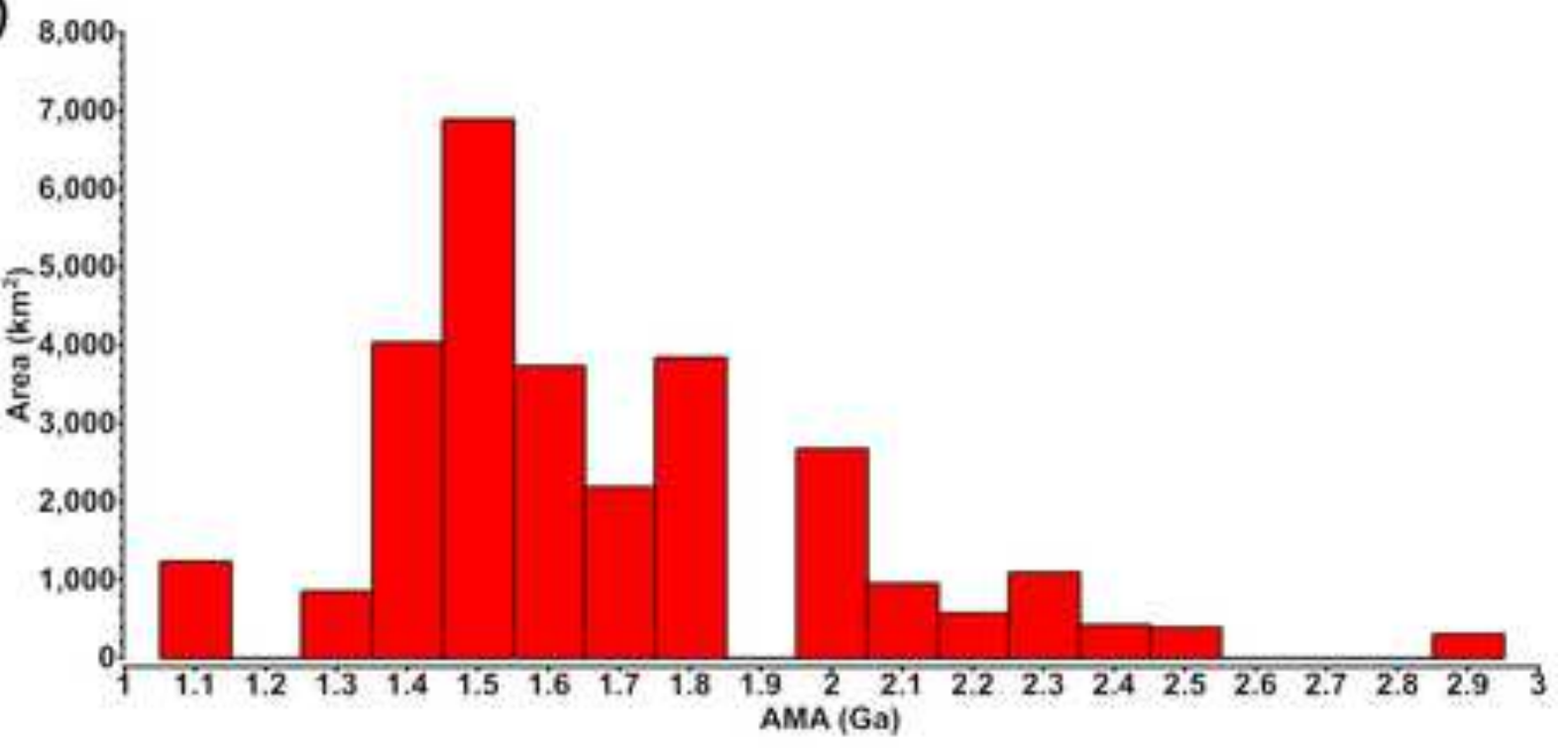



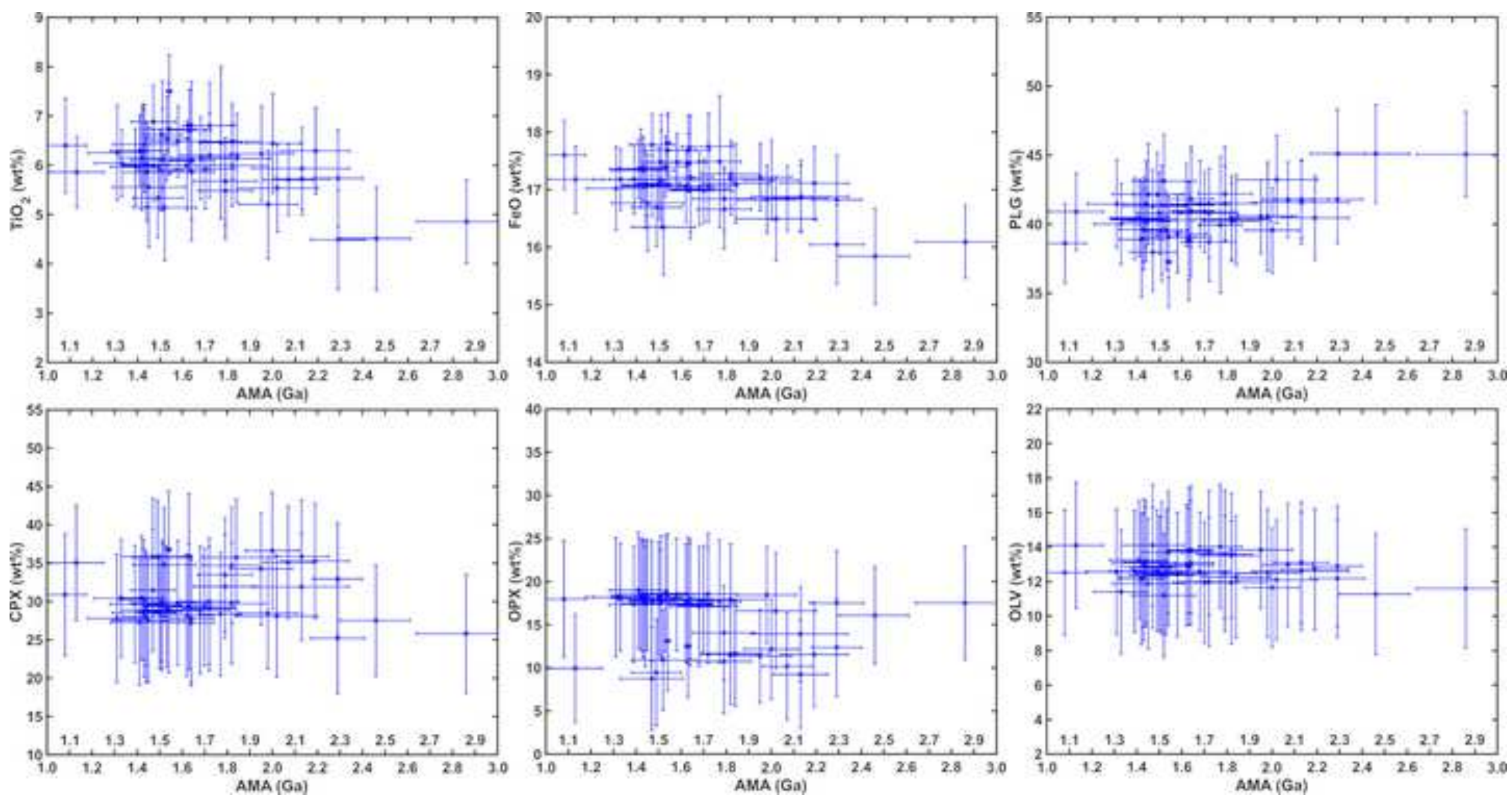


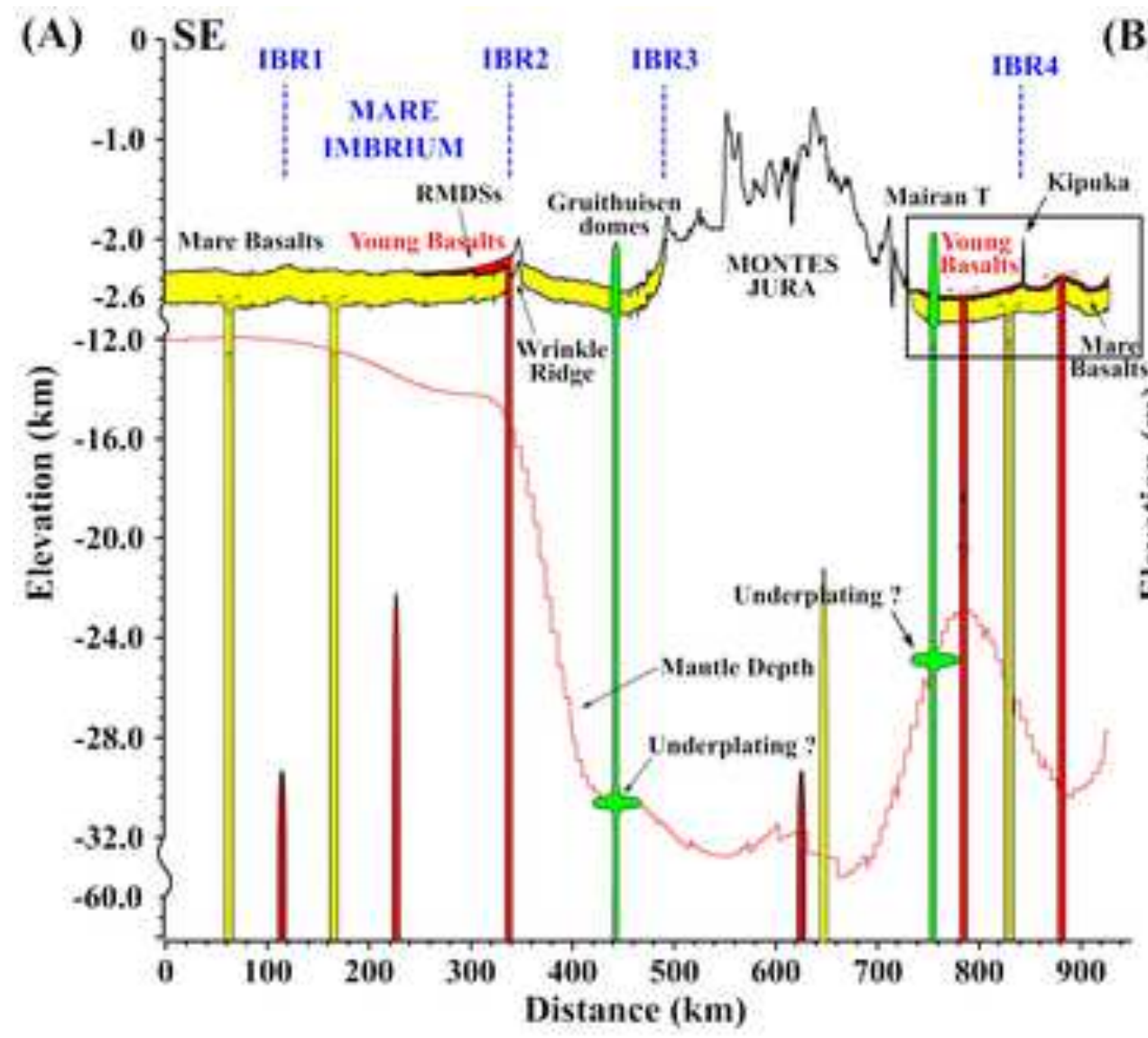

(B) $-1,8007 \quad$ NW

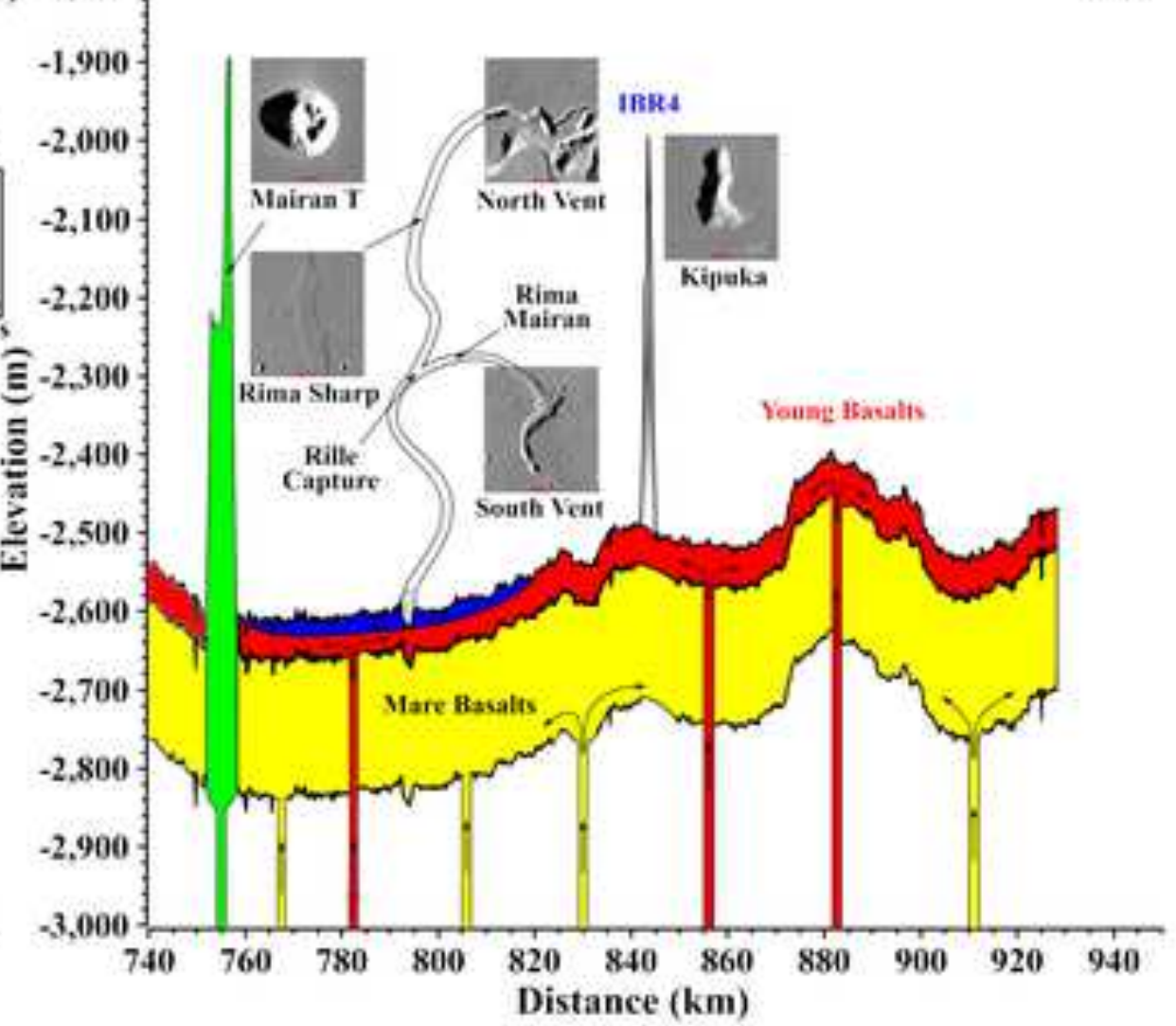


Click here to access/download Figure (high-resolution)

Figure 1.pdf 
Click here to access/download Figure (high-resolution)

Figure 2.pdf 
Click here to access/download Figure (high-resolution) Figure 3.pdf 
Click here to access/download Figure (high-resolution)

Figure 4.pdf 
Click here to access/download Figure (high-resolution) Figure 5.pdf 
Click here to access/download Figure (high-resolution) Figure 6.pdf 
Click here to access/download Figure (high-resolution) Figure 7.pdf 
Click here to access/download Figure (high-resolution)

Figure 8.pdf 
1 Table 1. Key questions for the analysis of the samples returned by CE-5. On the basis of the characteristics and the unique geologic setting of the CE-5 landing region, a series of fundamental questions that can be addressed are listed here.

\begin{tabular}{|c|c|}
\hline Chronology & $\begin{array}{l}\text { 1) What is the absolute age of the majority of Em4? 2) How many separate mare emplacement events } \\
\text { are recognizable in the samples? 3) How does this range of events compare to the observed AMA } \\
\text { variations? 4) What are the implications of the radiometric age characteristics for lunar and planetary } \\
\text { time scales, and the interplanetary flux? 5) Is there any evidence for silica-rich red spots materials, } \\
\text { and if so, what is their age? 6) Are there samples of impact basin ejecta (e.g., Iridum, Imbrium, etc.) } \\
\text { and what are their ages? 7) Is there any evidence of the presence of an ancient Procellarum impact } \\
\text { basin? }\end{array}$ \\
\hline Petrogenesis & $\begin{array}{l}\text { 1) Are the Em4 mare basalts characterized by elevated Th content, as suggested by the remote sensing } \\
\text { data, and thus derived from enhanced melting due to the high Th-content in the PKT Terrane? 2) Are } \\
\text { the Em4 mare basalts characterized by low Th-content more similar to that of Apollo/Luna basalts, } \\
\text { suggesting that they are derived from melting in deeper mantle source regions unassociated with the } \\
\text { PKT terrane? 3) What are the depths of source region melting estimated for the mare basalts? 4) Is } \\
\text { there any evidence for changes in source regions with time? 5) Is there any petrologic evidence for } \\
\text { shallow magma storage and staging? 6) What is the estimated volatile content of the Em4 and related } \\
\text { basalts? Are these consistent with the relatively low contents estimated by the sinuous rille source } \\
\text { regions and the lack of RMDS and IMPs? Is it variable? 7) Is there any evidence of KREEP basalts } \\
\text { and if so, what are their natures and ages? 8) Is there any evidence for Mg-suite rocks, and if so how } \\
\text { do they differ from those in the Apollo/Luna zone? }\end{array}$ \\
\hline Regional Setting & $\begin{array}{l}\text { 1) What is the range of Th content in the returned samples, their provenance, and their ages? 2) Was } \\
\text { the elevated Th content in the PKT important in the generation and emplacement of mare basalts in } \\
\text { the PKT, or are there other potential factors involved in their distribution and duration? 3) What are } \\
\text { the implications of the CE-5 sample analysis and characterization for the nature, structure, and } \\
\text { influence of the Procellarum-KREEP Terrane (PKT)? }\end{array}$ \\
\hline $\begin{array}{c}\text { Geodynamic \& } \\
\text { Thermal } \\
\text { Evolution }\end{array}$ & $\begin{array}{l}\text { 1) Are the Em4 and related mare basalt units magnetized and how do their magnetic characteristics } \\
\text { change with time? 2) Is there evidence to distinguish between the PKT region demagnetized magnetic } \\
\text { anomaly being the site of thermal (PKT-related) or impact demagnetization? 3) Does petrogenetic } \\
\text { evidence support deep sources for the mare basalt magmas related to a thickening lithosphere in later } \\
\text { lunar thermal evolution, or are other explanations required to account for their youth? }\end{array}$ \\
\hline $\begin{array}{c}\text { Regolith } \\
\text { Formation }\end{array}$ & $\begin{array}{l}\text { 1) Where does the Th reside in the regolith? In the mare basalt components, suggesting that the Th is } \\
\text { an inherent part of the basaltic units? Or is it concentrated in the non-mare regolith soils, suggesting } \\
\text { that the Th is transported into the regolith by lateral mixing from the highlands? 2) What is the range } \\
\text { of components in the young Em4 unit regolith and how do they compare with the older, more mature } \\
\text { regolith of the Apollo/Luna sites? 3) Is there any evidence of silica-rich red spot contributions, and if } \\
\text { so what is their nature and age? 4) Is there any evidence for mare basalt pyroclastic glass beads (both } \\
\text { quenched and crystallized) and if so, how do they relate to the petrology and age of the sampled mare } \\
\text { basalts? 5) What is the stratigraphy in the CE-5 core? How does it relate to local and regional impact } \\
\text { events, and how does it inform us about young regolith development? 6) On the basis of the } \\
\text { percentage of foreign components in the regolith, how do Em4 regolith processes compare to older, } \\
\text { more mature regolith? 7) Do any exotic non-mare components in the regolith relate to pre-mare craters } \\
\text { and basins in the region? If so, what is their provenance and age? }\end{array}$ \\
\hline
\end{tabular}


1 Table 2. CSFD absolute model ages $(\mathrm{Ga})$ of the Em4 unit from different studies.

\begin{tabular}{|c|c|c|c|c|c|c|}
\hline & \multicolumn{6}{|c|}{ Geologic Units } \\
\hline & $\operatorname{Im} 1$ & $\operatorname{Im} 2$ & $\operatorname{Im} 3$ & Em1 & Em3 & Em4 \\
\hline $\begin{array}{l}\text { Hiesinger et al. } \\
(2003,2011)\end{array}$ & 3.47 & 3.44 & 3.40 & & & 1.33 \\
\hline $\begin{array}{l}\text { Morota et al. } \\
\text { (2011) }\end{array}$ & I & l & / & l & l & $\begin{array}{l}1.91_{-0.11}^{+0.11} \text { (Model A) } \\
2.20_{-0.13}^{+0.13} \text { (Model B) }\end{array}$ \\
\hline $\begin{array}{l}\text { Qian et al. } \\
\text { (2018) }\end{array}$ & $3.42_{-0.02}^{+0.02}$ & $3.39_{-0.02}^{+0.02}$ & $3.16_{-0.09}^{+0.06}$ & $2.30_{-0.10}^{+0.10}$ & $1.51_{-0.07}^{+0.07}$ & $1.21_{-0.03}^{+0.03}$ \\
\hline Wu et al. (2018) & $3.48_{-0.04}^{+0.03}$ & $3.47_{-0.02}^{+0.02}$ & & $2.03_{-0.33}^{+0.33}$ & $2.06_{-0.24}^{+0.24}$ & $1.49_{-0.17}^{+0.17}$ \\
\hline $\begin{array}{l}\text { T. A. Giguere et } \\
\text { al. (2020) }\end{array}$ & l & l & l & l & l & 3.33 \\
\hline Jia et al. (2020) & $3.23_{-0.042}^{+0.035}$ & $3.27_{-0.025}^{+0.022}$ & $3.35_{-0.079}^{+0.053}$ & $2.02_{-0.16}^{+0.16}$ & $2.54_{-0.50}^{+0.41}$ & $2.07_{-0.027}^{+0.026}$ \\
\hline $\begin{array}{l}\text { CURRENT } \\
\text { STUDY }\end{array}$ & l & l & l & l & / & $1.53_{-0.027}^{+0.027}$ \\
\hline \multicolumn{7}{|c|}{ Compare with Wu et al. (2018) } \\
\hline & \multicolumn{6}{|c|}{ Subunits } \\
\hline & Subunit 10 & Subunit 11 & Subunit 18 & Subunit 19 & Subunit 26 & Subunit 27 \\
\hline Wu et al. (2018) & $1.53_{-0.069}^{+0.069}$ & $1.23_{-0.036}^{+0.036}$ & $1.28_{-0.051}^{+0.051}$ & $1.67_{-0.072}^{+0.072}$ & $2.02_{-0.078}^{+0.078}$ & $1.94_{-0.072}^{+0.072}$ \\
\hline $\begin{array}{l}\text { CURRENT } \\
\text { STUDY }\end{array}$ & $1.49_{-0.11}^{+0.11}$ & $1.13_{-0.12}^{+0.12}$ & $1.47_{-0.14}^{+0.14}$ & $1.79_{-0.12}^{+0.12}$ & $2.13_{-0.12}^{+0.12}$ & $2.07_{-0.11}^{+0.11}$ \\
\hline
\end{tabular}


Click here to access/download Supplementary material for online publication only \#5491-CE5 Young Mare Basalts-SOM (Final 11-1820).docx 
CRediT authorship contribution statement

Y.Q.: Conceptualization, Methodology, Investigation, Data Curation, Writing Original Draft, Writing - Review \& Editing. L.X.: Conceptualization, Writing Original Draft, Writing - Review \& Editing, Supervision, Project administration, Funding acquisition. J.W.H.: Conceptualization, Validation, Writing - Original Draft, Writing - Review \& Editing, Supervision. C.H.v.B.: Methodology, Validation, Investigation, Writing - Review \& Editing. H.H.: Methodology, Validation, Investigation, Writing - Review \& Editing. L.W.: Methodology, Validation, Investigation, Writing - Review \& Editing. 


\section{Declaration of interests}

$\bigotimes$ The authors declare that they have no known competing financial interests or personal relationships that could have appeared to influence the work reported in this paper.

$\square$ The authors declare the following financial interests/personal relationships which may be considered as potential competing interests:

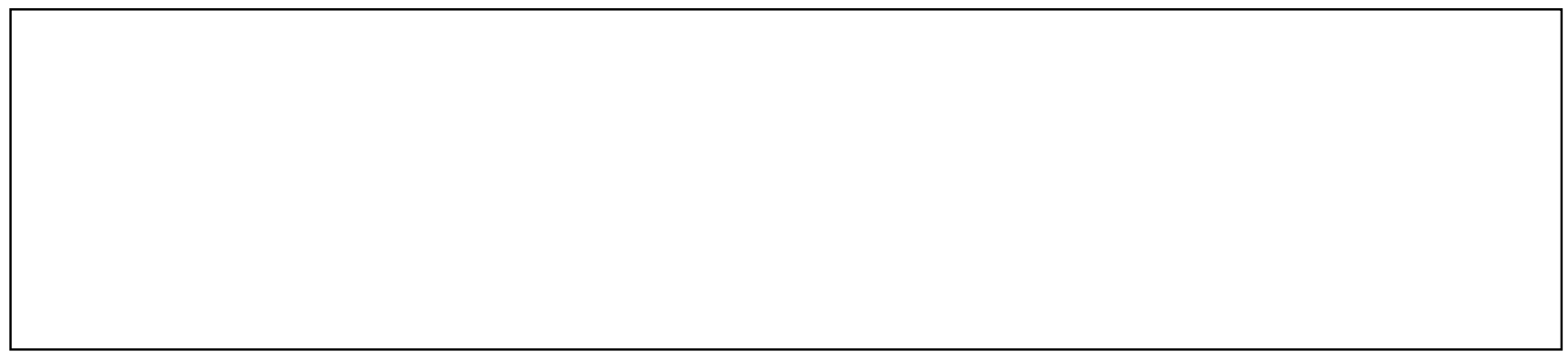

